\title{
Nonhypoxic regulation and role of hypoxia-inducible factor 1 in aromatase inhibitor resistant breast cancer
}

\author{
Armina A Kazi ${ }^{1,5}$, Rabia A Gilani ${ }^{1}$, Amanda J Schech', Saranya Chumsri ${ }^{2,3}$, Gauri Sabnis ${ }^{1,3}$, Preeti Shah ${ }^{1,3}$,
} Olga Goloubeva ${ }^{3,4}$, Shari Kronsberg ${ }^{4}$ and Angela H Brodie ${ }^{1,3,6^{*}}$

\begin{abstract}
Introduction: Although aromatase inhibitors (Als; for example, letrozole) are highly effective in treating estrogen receptor positive (ER+) breast cancer, a significant percentage of patients either do not respond to Als or become resistant to them. Previous studies suggest that acquired resistance to Als involves a switch from dependence on ER signaling to dependence on growth factor-mediated pathways, such as human epidermal growth factor receptor-2 (HER2). However, the role of HER2, and the identity of other relevant factors that may be used as biomarkers or therapeutic targets remain unknown. This study investigated the potential role of transcription factor hypoxia inducible factor 1 (HIF-1) in acquired Al resistance, and its regulation by HER2.

Methods: In vitro studies using Al (letrozole or exemestane)-resistant and Al-sensitive cells were conducted to investigate the regulation and role of HIF-1 in Al resistance. Western blot and RT-PCR analyses were conducted to compare protein and mRNA expression, respectively, of ERa, HER2, and HIF-1a (inducible HIF-1 subunit) in Al-resistant versus Al-sensitive cells. Similar expression analyses were also done, along with chromatin immunoprecipitation (ChIP), to identify previously known HIF-1 target genes, such as breast cancer resistance protein (BCRP), that may also play a role in Al resistance. Letrozole-resistant cells were treated with inhibitors to HER2, kinase pathways, and ERa to elucidate the regulation of HIF-1 and BCRP. Lastly, cells were treated with inhibitors or inducers of HIF-1a to determine its importance.

Results: Basal HIF-1a protein and BCRP mRNA and protein are higher in Al-resistant and HER2-transfected cells than in Al-sensitive, HER2- parental cells under nonhypoxic conditions. HIF-1a expression in Al-resistant cells is likely regulated by HER2 activated-phosphatidylinositide-3-kinase/Akt-protein kinase B/mammalian target of rapamycin (PI3K/Akt/mTOR) pathway, as its expression was inhibited by HER2 inhibitors and kinase pathway inhibitors. Inhibition or upregulation of HIF-1a affects breast cancer cell expression of BCRP; Al responsiveness; and expression of cancer stem cell characteristics, partially through BCRP.
\end{abstract}

Conclusions: One of the mechanisms of Al resistance may be through regulation of nonhypoxic HIF-1 target genes, such as BCRP, implicated in chemoresistance. Thus, HIF-1 should be explored further for its potential as a biomarker of and therapeutic target.

\footnotetext{
* Correspondence: abrodie@umaryland.edu

${ }^{1}$ Department of Pharmacology and Experimental Therapeutics, University of

Maryland, Baltimore, MD 21201, USA

${ }^{3}$ School of Medicine, University of Maryland Marlene and Stewart

Greenebaum Cancer Center, Baltimore, MD 21201, USA

Full list of author information is available at the end of the article
} 


\section{Introduction}

Breast cancer is the most prevalent form of cancer among women in the United States and second leading cause of cancer related deaths [1]. Approximately $70 \%$ to $80 \%$ of breast cancers express estrogen receptor $(\mathrm{ER}+)$ and, consequently, are estrogen-dependent in their growth. Endocrine/hormonal therapies have proven effective in treating ER + breast cancers. Selective estrogen receptor modulators (SERMS), such as tamoxifen, inhibit estrogen action on breast cancer cells by blocking ER + signaling. Alternatively, aromatase inhibitors (AIs; for example, letrozole, anastrozole, and exemestane) reduce circulating levels of estrogen by inhibiting the conversion of androgens to estrogen by the enzyme aromatase $[2,3]$. Comparing the efficacy of tamoxifen versus AIs, a number of clinical studies have shown that AIs are superior in terms of disease free survival, time to recurrence and prevention of contralateral breast cancer $[4,5]$. In the adjuvant setting, AIs are less toxic with minimal adverse effects compared to chemotherapy and provide protection against development of contralateral breast cancer. AIs are now first-line treatments for ER + breast cancer in post-menopausal women [6]. However, a significant percentage (range 30\% to $65 \%$ ) of patients either does not respond to AIs [7] or becomes resistant to them [8-10].

Studies from this lab and others suggest that resistance to AIs occurs after a switch from dependence on ER signaling to dependence on growth factor-mediated pathways, such as human epidermal growth factor receptor-2 (HER2), a member of the membrane epidermal growth factor receptor (EGFR) family of receptor tyrosine kinases, and insulin-like growth factor receptor (IGFR) [9-11]. Pre-clinical [12] and clinical [10] studies have explored HER2 inhibitors, trastuzumab and lapatinib, as treatments for letrozole-resistant breast cancer. Preclinically, our laboratory has shown that trastuzumab alone or in combination with letrozole decreased HER2 expression, restored ER $\alpha$ expression, and inhibited tumor growth of MCF-7Ca xenografts that became resistant to letrozole [13]. Clinically, it has been shown that lapatinib in combination with letrozole significantly increased progression-free survival in patients versus letrozole alone as first-line therapy for hormone receptor- and HER2-positive postmenopausal metastatic breast cancer $[10,14]$. However, studies with de novo HER2+ breast cancer (that is, not HER2+ breast cancer of acquired AI resistance) indicate that resistance can develop to HER2 inhibitors as well $[15,16]$. Thus, although it has yet to be studied, there may be a risk of developing resistance to second-line HER2 inhibitor therapy in patients who have already acquired resistance to first-line AI therapy. As a membrane receptor, HER2 can affect many cellular pathways, some of which may not be directly involved in the development of AI resistance. Targeting another factor downstream of HER2 that more directly mediates effects specific and essential to the development of AI resistance may be as effective as targeting HER2 itself, while not having the same level of risk of producing second-line acquired resistance. Currently, the mechanism by which HER2 is involved in AI resistance remains unclear. It is, therefore, important to: 1) further elucidate the HER2mediated pathway that contributes to AI resistance, particularly characteristics associated with AI resistant breast cancer cells; and 2) identify other potential factors involved that may serve as novel molecular biomarkers and therapeutic targets.

One factor that may be involved in HER2-mediated AI resistance is HIF-1, a heterodimeric transcription factor made up of an inducible alpha $(\alpha)$ subunit and a constitutively expressed beta ( $\beta$ ) subunit [17]. HIF-1 $\alpha$ is normally kept low in cells by proteosomal degradation, but lack of sufficient oxygen levels (hypoxia, for example, 1\% to $2 \% \mathrm{O}_{2}$ ) prevents this degradation. This leads to increased intracellular HIF- $1 \alpha$ protein levels, formation of HIF-1, and activation of HIF-1 target genes important for cell survival, metabolic adaptation and angiogenesis. Interestingly, HIF-1 expression and/or activation can also be regulated by growth factors, hormones and cytokines independent of $\mathrm{O}_{2}$ levels. For example, ER $\alpha$ - and HIF-1mediated signaling pathways are known to interact antagonistically [18,19] and cooperatively [20-23]. EGFR and HER2, as well as kinase signaling pathways, such as the MAPK and PI3K/Akt pathways, have also been shown to regulate HIF-1 $\alpha$ expression and activity $[22,24,25]$.

The role of hypoxia-regulated HIF-1 in cancer has been well studied. This is particularly relevant to sizable tumors whose cancer cells are too distant from existing blood vessels to get enough oxygen and nutrients [26]. Hypoxia and/or HIF-1 have been implicated in increased patient mortality and disease progression [27]. Their involvement in tumor formation and metastasis [28,29], and regulation of cancer stem cells $[28,30]$ and stem cell markers, such as breast cancer resistant protein (BCRP) $[27,30,31]$, has also been demonstrated. However, nonhypoxic regulation of HIF-1 and its importance in cancer remains largely unknown. Specific to this study, the regulation and role of nonhypoxic HIF-1 in breast cancer cell resistance to AIs, specifically letrozole, has yet to be explored. Using a letrozole-resistant cell line developed from xenograft tumors in our laboratory, this current study tested the overall hypothesis that nonhypoxic HIF-1 is an essential factor in HER2-mediated letrozole resistance. More specifically, in letrozole-responsive tumors, the switch from ER $\alpha$ to HER2-dependent signaling increases HIF- $1 \alpha$ expression, independent of nutrient or oxygen availability. HIF-1 then acts as a key transcription factor activating target genes involved in processes that promote letrozole resistance. 


\section{Methods}

\section{Cells and reagents}

Cell culture

Cell lines (and their ER/HER2 status) used are listed in Table 1. MCF-7Ca cells obtained from the laboratory of Dr. Chen through institutional agreement (City of Hope, Duarte, CA, USA) are MCF-7 cells stably transfected with the human placental aromatase gene [32,33]. Aromatase is the enzyme that converts androgens to estrogen. Transfection of the aromatase gene does not affect ER/HER2 status, ER activation, or estrogen-dependence of MCF-7 cells, but it does allow MCF-7 cells to proliferate in response to androgens (for example, androstenedione) and be sensitive to growth inhibitor effects of aromatase inhibitors [33]. MCF$7 \mathrm{Ca}$ cells were maintained in (D)MEM $1 \times$ high glucose (Invitrogen, Grand Island, NY) supplemented with 5\% fetal bovine serum (FBS), 1\% penicillin/streptomycin (P-S), and $700 \mu \mathrm{g} / \mathrm{mL}$ geneticin selective antibiotic (G418). Longterm letrozole-treated (LTLTCa) cells, developed in our laboratory [34], are letrozole-resistant breast cancer cells isolated from MCF-7Ca mouse xenograft tumors treated for 56 weeks with letrozole and that have become resistant to the growth inhibitory effects of letrozole. LTLTCa cells were maintained in phenol red-free (PRF) modified Improved Minimal Essential Media (IMEM) (Invitrogen, Grand Island, NY) supplemented with 5\% charcoal dextran-treated FBS (CDT-FBS), 1\% P-S, $750 \mu \mathrm{g} / \mathrm{mL}$ G418, and $1 \mu \mathrm{M}$ letrozole. LTLTCa cells can be compared to MCF-7Ca cells in experiments since they originated from the MCF-7Ca cell population and their expression of ER $\alpha$ and HER2 returns to levels similar to that of MCF-7Ca cells after letrozole withdrawal [35]. MCF-7 cells obtained from American Type Culture Collection (ATCC) were maintained in (D)MEM 1× high glucose (Invitrogen, Grand Island, NY) supplemented with 5\% FBS and 1\% P-S. Hc7 cells were developed in our laboratory; they are MCF-7 cells transfected with the HER2 gene and overexpress HER2 [36]. Hc7 cells were maintained in (D)MEM 1× high glucose (Invitrogen, Grand Island, NY) supplemented with $5 \%$ FBS, 1\% P-S, and $500 \mu \mathrm{g} / \mathrm{ml}$ hygromycin. AC1 cells are

Table 1 ERa and HER2 status and aromatase inhibitorsensitivity of cell lines used

\begin{tabular}{lccc}
\hline Cell line & ERa status & HER2 status & Al-sensitivity \\
\hline MCF-7Ca & + & - & Yes \\
LTLT-Ca & - & + & No (to letrozole) \\
MCF7 & + & - & Yes \\
MCF7 / HER2 & + & + & ND \\
AC1 & + & - & Yes \\
AC1-EX R & + & + & No (to exemestane)
\end{tabular}

ERa, estrogen receptor alpha; HER2, human epidermal growth factor receptor 2; ND: not determined. another set of MCF-7 cells stably transfected with the human placental aromatase gene [37]. Similar to MCF-7Ca cells, AC1 cells are ER+/HER2-, proliferate in response to estrogen or androstenedione, express the aromatase enzyme and are sensitive to aromatase inhibitors [38]. AC1 cells, however, were created in our laboratory rather than Dr. Chen's, and they express higher levels of aromatase (data not shown). AC1 cells are maintained in (D)MEM 1x high glucose (Invitrogen, Grand Island, NY) supplemented with 5\% FBS, 1\% P-S, and $800 \mu \mathrm{g} / \mathrm{mL}$ G418. AC1-exemestane resistant (AC1-ExR) cells, developed in our laboratory, are exemestane-resistant cells isolated from AC1 mouse xenograft tumors treated for approximately 10 weeks with exemestane maintained in PRF modified IMEM (Invitrogen, Grand Island, NY) supplemented with 5\% CDT-FBS, 1\% P-S, $800 \mu \mathrm{g} / \mathrm{mL}$ G418, and $5 \mu \mathrm{M}$ exemestane.

For experiments determining the effect of oxygen tension on protein expression, MCF-7Ca and LTLTCa cells were plated in passage media and incubated either under normal $\left(20 \% \mathrm{O}_{2}\right.$ at $\left.37^{\circ} \mathrm{C}\right)$ or more physiological $\left(5 \% \mathrm{O}_{2}\right.$; using a hypoxia chamber) cell culture conditions for 24 hours. MCF-7 cells used to generate $\mathrm{MC}-7 \mathrm{Ca}$ and AC1 cells were obtained from the ATCC and, thus, did not require ethical approval or patient consent.

\section{Reagents}

The following drugs were used: letrozole (Novartis, NY, USA); lapatinib (GlaxoSmithKline Pharmaceutical, Brentford, Middlesex, United Kingdom); trastuzumab (Genentech, San Francisco, CA); exemestane (Pfizer, NY, USA); cycloheximide (\#C1988), actinomycin D (\#A9415), and cobalt chloride $\left(\mathrm{CoCl}_{2} ; \#\right.$ C8661) (all from Sigma, St. Louis, MO). The following antibodies were used in western blot analyses: HER2 (\#04-1127) and BCRP

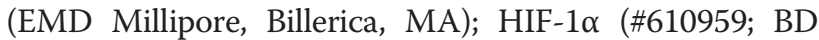
Biosciences); ER $\alpha$ (\#8644; Cell Signaling Technology, Danvers, MA); phosphorylated and total ERK1/2, Akt (\#4058 and \#4685), mTOR (\#2971 and \#2972) and p70 S6 kinase (\#9205 and \#9202) all from Cell signaling Technology, Danvers, MA); and $\beta$-actin (\#4970; Cell Signaling Technology, Danvers, MA).

\section{Western blot analysis}

Plated cells were washed with ice-cold PBS and then lysed with radioimmunoprecipitation (RIPA) buffer containing protease (\#11836145001) and phosphatase inhibitors (\#4906837001) (both from Roche Applied Sciences, Indianapolis, IN) by sonication and incubation for 20 minutes at $4^{\circ} \mathrm{C}$. Lysed samples were centrifuged at $14,000 \mathrm{rpm}$ for 20 minutes at $4^{\circ} \mathrm{C}$ to collect protein lysates (supernatant). A total of 10 to $40 \mu \mathrm{g}$ of protein underwent 10\% SDS-polyacrylamide gel electrophoresis (SDS-PAGE) and was transferred to a polyvinylidene difluoride membrane (PVDF; 
\#IPVH00010 Millipore, Billerica, MA). The resulting blots were probed with specific mouse or rabbit primary antibodies and either goat anti-mouse or -rabbit secondary antibodies conjugated to horseradish peroxidase (\#17 21011 and\#172-1019; Biorad, Hercules, CA), respectively. Blots were developed using SuperSignal West Pico Chemiluminescent Substrate (\#34080; Thermo Scientific, Waltham, MA). Blots that were to be re-probed were stripped with Restore Western Blot Stripping Buffer (\#21059; Thermo Scientific, Waltham, MA) for 40 minutes at room temperature prior to incubation with another primary antibody. Densitometry was performed on each blot using either ImageQuant or ImageJ.

\section{Reverse transcripase-polymerase chain rection RNA extraction and reverse transcription (RT)}

RNA was extracted and purified using the RNeasy Mini Kit (\#74104; Qiagen, Valencia, CA). RNA was reverse transcribed to complementary DNA (cDNA) using 200U of Moloney murine leukemia virus reverse transcriptase (\#28025013; Invitrogen, Grand Island, NY) and incubating at $37^{\circ} \mathrm{C}$ for one hour.

\section{Real-time PCR}

mRNA expression analyses were carried out by real-time PCR using a DNA Opticon system (M) Research, Waltham, MA) and using DyNAmo SYBR green qPCR mix (New England Biolabs, Ipswich, MA). Standard curves were generated by serially diluting the sample expected to have the most amount of the PCR product. The yield of product for each unknown sample was calculated by applying its threshold cycle, or $\mathrm{C}(\mathrm{T})$, value to the standard curve using the Opticon Monitor analysis software (version 1.01, MJ Research, Waltham, MA). Values were normalized to corresponding 18S rRNA values and expressed as the fold increase relative to controls. Primers for HER2, HIF-1 $\alpha$, BCRP, GAPDH, BMI-1, Nanog and TWIST were obtained from (Sigma, St. Louis, MO or Qiagen Valencia, CA).

\section{Chromatin immunoprecipitation assay}

For the in vitro chromatin immunoprecipitation (ChIP) assay, the treated cells were washed with DPBS and fixed with $1 \%$ formaldehyde/dulbecco's phosphate buffered saline (DPBS) for 10 minutes at $37^{\circ} \mathrm{C}$, after which the cells were washed with ice-cold DPBS containing protease inhibitors. The cells were collected into $1 \mathrm{~mL}$ DPBS and pelleted by centrifugation at $6,000 \mathrm{rpm}$ for five minutes at $4^{\circ} \mathrm{C}$. The cell pellet was resuspended in nuclear lysis buffer (ChIP kit, \#17-295 Millipore, Billerica, MA) and incubated on ice for 15 minutes. Samples were sonicated on ice for $7 \times 10$-second cycles, with 20 -second pauses between each cycle. The sonicated samples were centrifuged at $14,000 \mathrm{rpm}$ for 10 minutes at $4^{\circ} \mathrm{C}$. The sonicated samples were diluted 1:10 with dilution buffer (ChIP kit) before being immunocleared in a solution containing protein A- or G-Sepharose slurry (\#16-156 and \#16-266, respectively; Millipore, Billerica, MA) in Tris/ethylenediaminetetraacetic acid (EDTA) buffer, salmon sperm DNA (\#15632011; Invitrogen, Grand Island, NY), and normal mouse or rabbit serum (\#M5905 and \#R9133; Sigma, St. Louis, MO) for two hours at $4^{\circ} \mathrm{C}$. Immunocleared supernatants were incubated overnight at $4^{\circ} \mathrm{C}$ with anti-HIF-1 $\alpha$ antibody (\#610959; BD Biosciences). Protein A- or G-Sepharose beads and salmon sperm DNA were then added and incubated for one hour at $4^{\circ} \mathrm{C}$. The beads were then washed sequentially with $1 \mathrm{~mL}$ each of wash buffers (ChIP kit). The protein-DNA complexes were eluted by twice incubating the beads in an elution buffer for 10 minutes at room temperature with vigorous mixing. To separate immunoprecipitated protein and DNA, the pooled elutes were incubated at $65^{\circ} \mathrm{C}$ overnight. The DNA was purified using the QIAquick PCR Purification kit (\#28106; Qiagen Valencia, CA). The yield of target region DNA in each sample after ChIP was analyzed by real-time $\mathrm{PCR}$ using primers for a region of BCRP promoter that contains a HIF-1 response element (Invitrogen, Grand Island, NY) or a negative control open reading frame (ORF)-free intergenic region (ChIP-qPCR Human IGX1A Negative Control primers (\#GPH100001C(-)01A, Qiagen, Valencia, CA).

\section{Mammosphere assay}

The mammosphere assay was performed using reagents from Stem Cell Technologies (Vancouver, CA), according to the manufacturer's instructions. Single cells were suspended in complete Mammocult media according to the manufacturer's instructions (\#05620) and plated in ultra low attachment plates (\#CLS3471; Corning, Tewksbury, MA) at a density of 10,000 to 20,000 cells $/ \mathrm{mL}$. Media were replenished every three days. Mammospheres were counted after at least seven days and up to three to four weeks. Spheres with a colony count of at least 50 cells were considered mammospheres.

\section{Statistical analysis}

All experiments were performed two to three times, with multiple replicates at each time point (total of $n$ $=4$ to 6 independent samples). Thus, quantified values are means of $n=4$ to 6 independent samples/ group with standard deviations (SD). Statistical analyses were performed using Graph Pad Prism software and included: 1) a two-sided t-test to compare two groups (for example, MCF-7Ca versus LTLTCa); 2) a 
one-way analysis of variance (ANOVA) with Tukey's adjustment to compare three or more groups (for example, different treatment types, time points, and so on); and 3) a two-way ANOVA with Bonferroni adjustment (for example, different cell types and treatments or genes). For mRNA stability, the linear mixed-effects models approach was used. To assure approximate normality, the logarithmic transformation was applied to the normalized value of mRNA, that is, for each cell line, mRNA expression at each actinomycin $\mathrm{D}$ time point was normalized using the corresponding vehicle-treated samples. Average mRNA expressions were estimated and compared at the prespecified time-points (Additional file 1: Table S1.1 and Table S1.2), the trends over time were determined for HIF- $\alpha$ mRNA and BCRP mRNA. All required models' diagnostics were performed. There were fixed effects for time, experiment, cell lines and interactions between time and cell lines. The models had hierarchical structure as repeated measurements were taken within a well, nested within time, cell line, and experiment. The compound symmetry was chosen as appropriate to model the variance structure of the random effects. Statistical tests were two-sided. Analyses were conducted using SAS (v.9.22, SAS Inc., NC, USA). The alpha level applied in all statistical analyses was $P<0.05$.

\section{Results}

LTLTCa cells have higher HIF-1a protein expression than MCF-7Ca cells under nonhypoxic conditions

Previous studies have shown that a decrease in ER $\alpha$ and an increase in HER2 protein expression is associated with acquired AI-resistance [9-11], represented in this current study by LTLTCa cells. To determine whether HIF-1 expression is also associated with acquired AIresistance, protein expression of the inducible HIF- $1 \alpha$ subunit in LTLTCa and MCF-7Ca cells was determined. As expected, LTLTCa cells had $0.3 \pm 0.02$-fold ER $\alpha$ $(P<0.0001)$; and $18.0 \pm 5.5$-fold HER2 $(P=0.002)$ protein levels compared to letrozole-sensitive parental MCF-7Ca cells under normal cell culture conditions (that is, nonhypoxic; 20\% $\mathrm{O}_{2}$ ) (Figure 1A). LTLTCa cells also had $15.7 \pm 5.9$-fold (versus $1.0 \pm 1.4 \mathrm{MCF}-7 \mathrm{Ca}$ at $20 \% \mathrm{O}_{2}$ ) higher basal levels of HIF-1 $\alpha$ protein than their parental MCF-7Ca cells, which expressed little to no HIF- $1 \alpha$ (Figure 1A).

Since oxygen levels in normal tissue $[39,40]$, including the breast [26,41], range from $2 \%$ to $5 \%$, and HIF- $1 \alpha$ protein is known to be sensitive to $\mathrm{O}_{2}$ levels [17], protein expression at $5 \% \quad \mathrm{O}_{2}$ was also determined (Figure 1A). ER $\alpha$ and HER2 levels in both LTLTCa and MCF-7Ca cells remained unchanged when the percent $\mathrm{O}_{2}$ was reduced to more physiological levels. HIF-1 $\alpha$ expression, in contrast and as expected, increased in both

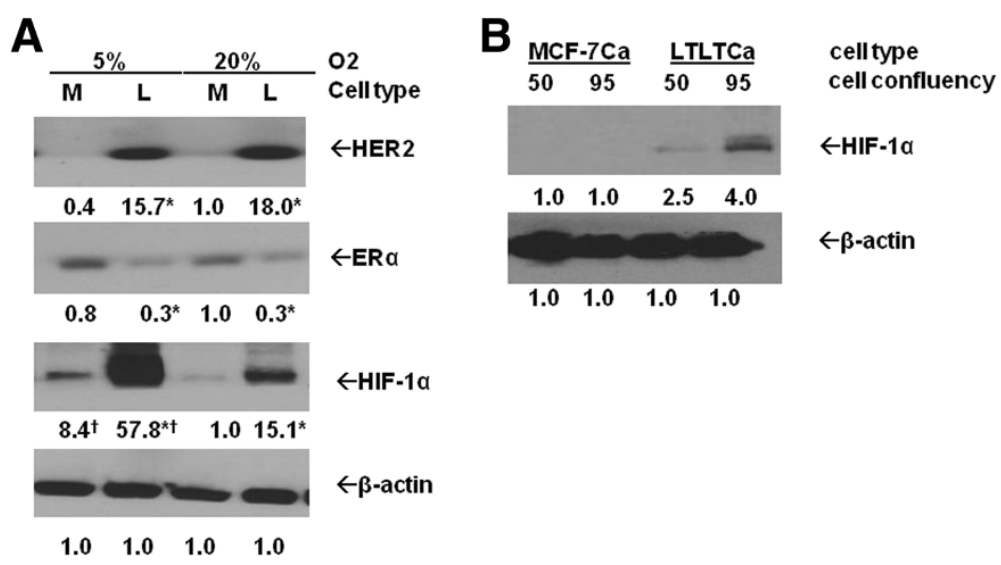

Figure 1 Comparison of protein expression in parental MCF-7Ca and LTLTCa cells under different oxygen tension and cell confluency. A) Parental MCF-7Ca and LTLTCa cells were plated and cultured in their respective passage media under either $5 \% \mathrm{O}_{2}$ (in vivo normoxic/ physiological conditions) or $20 \% \mathrm{O}_{2}$ (normal, nonhypoxic cell culture conditions). Total protein was extracted and HER2, ERa, HIF-1a and $\beta$-actin were analyzed by Western blot analysis. Shown are representative blots and overall densitometry results of $n=6$ independent cell samples/group. Densitometry results are expressed as mean fold-change in protein levels compared to MCF-7Ca cells in $20 \% \mathrm{O}_{2}$ after normalization to $\beta$-actin (mean \pm SD of $\mathrm{n}=6$ independent cell samples/group; *versus MCF-7Ca and + versus $20 \% \mathrm{O}_{2} ;$ HER2 effect of cell type $P=0.0002$, effect of \% $\mathrm{O}_{2}$ $P=.5749$, interaction between cell type and $\% \mathrm{O}_{2} P=.7337$; ERa effect of cell type $P<0.0001$, effect of $\% \mathrm{O}_{2} P=.2879$, interaction between cell type and $\% \mathrm{O}_{2} P=.2016$; HIF-1a effect of cell type $P=0.0024$, effect of $\% \mathrm{O}_{2} P=0.0087$, interaction between cell type and\% $\mathrm{O}_{2} P=0.0413$; two-way ANOVA). B) LTLTCa and parental MCF-7Ca cells were plated and cultured in their respective passage media at 1X or 2X density. Total protein was extracted when 2 X density plates reached approximately $90 \%$ to $95 \%$ confluency, and, consequently, 1 X density plates reached approximately $50 \%$ to $60 \%$ confluency. HIF-1a and $\beta$-actin protein were analyzed by Western blot. Densitometry results are expressed as mean fold-change compared to MCF-7Ca cells after normalization to $\beta$-actin. (mean $\pm S D, n=6$ independent cell samples/group; effect of cell confluency $P=0.0006$, effect of cell type $P<0.0001$, interaction between cell confluency and cell type $P=0.0006$, two-way ANOVA). ANOVA, analysis of variance; ERa, estrogen receptor alpha; HER2, human epidermal growth factor receptor 2; HIF-1a, hypoxia inducible factor 1 a subunit; n, number; SD, standard deviation. 
MCF-7Ca and LTLTCa cells (8.4 \pm 3.1 -fold and $57.8 \pm$ 2.2 -fold versus MCF-7Ca at $20 \% \mathrm{O}_{2}$, Figure $1 \mathrm{~A}$ ). Nevertheless the fold differences in HIF- $1 \alpha$ expression between LTLTCa cells and MCF-7Ca persisted and were significant.

Lastly, since HIF-1 $\alpha$ protein expression can also be affected by cell density/confluency $[42,43]$, protein expression in LTLTCa and MCF-7Ca cells at both approximately $50 \%$ and $95 \%$ confluencies were also analyzed. LTLTCa cells had higher levels of HIF-1 $\alpha$ protein than MCF-7Ca cells under nonhypoxic conditions at both cell densities $(P<0.0001$, Figure $1 \mathrm{~B})$. Furthermore, while MCF-7Ca cells still had little or no HIF- $1 \alpha$ protein at $95 \%$ confluency, LTLTCa cells exhibited a significant increase in HIF-1 $\alpha \quad(P=0.0006$; Figure 1B). These results suggest that: 1) letrozoleresistant LTLTCa cells basally and inherently have higher HIF- $1 \alpha$ protein expression than letrozole-sensitive MCF$7 \mathrm{Ca}$ cells regardless of $\mathrm{O}_{2}$ levels or cell density; and 2)
LTLTCa cells are more sensitive to inducers of HIF-1 $\alpha$ expression, such as decreased $\mathrm{O}_{2}$ levels and cell density/ confluency.

\section{HIF-1a expression in LTLTCa cells is due to increased protein synthesis}

Elevated HIF-1 $\alpha$ protein expression in cells can result from increased protein stability and/or synthesis [44]. In LTLTCa cells, higher levels of HIF- $1 \alpha$ may be due to increased protein synthesis (for example, increased mRNA translation to protein) for several reasons. First, unlike HER2 and ER $\alpha$ mRNA, HIF- $1 \alpha$ mRNA expression was not significantly different between LTLTCa cells and MCF-7Ca cells (Figure 2A). This rules out increased $H I F-1 \alpha$ gene transcription as the basis for increased HIF- $1 \alpha$ protein. Second, overall through 16 hours of actinomycin D treatment HIF- $1 \alpha$ mRNA was not more stable in LTLTCa cells compared to MCF-7Ca cells (Figure $2 \mathrm{~B}$ and Additional
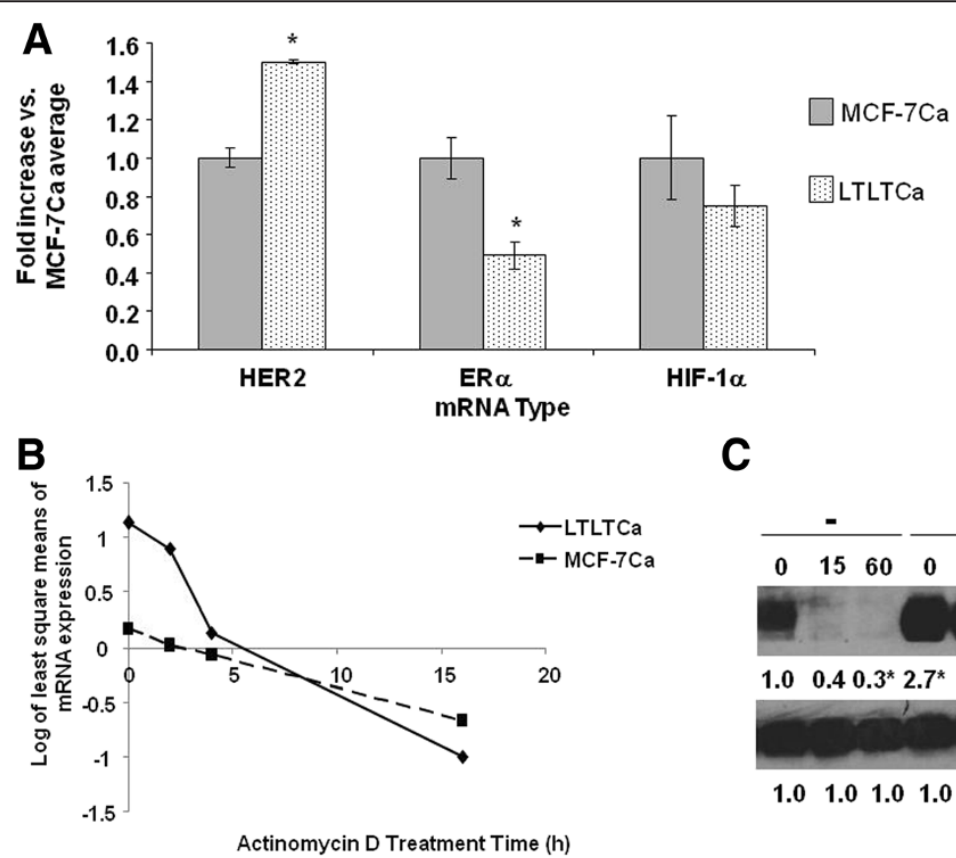

C

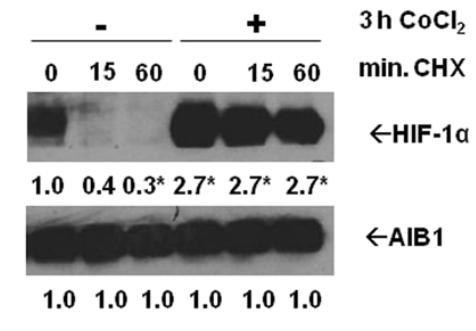

Figure 2 Comparison of HIF-1a mRNA expression and stability in LTLTCa and MCF-7Ca cells. A) LTLTCa and MCF-7Ca cells were plated and cultured in their respective passage media under normal cell culture (nonhypoxic) conditions. Total RNA was extracted and HER2, ERa, HIF-1a and $18 \mathrm{~S}$ rRNA were analyzed by real-time RT-PCR analysis. Results shown are expressed as the mean fold-change in mRNA levels compared with MCF-7Ca cells after normalization to $18 \mathrm{~S}$ rRNA (mean \pm SD of $n=6$ independent cell samples/group; *versus MCF-7Ca; effect of gene type $P<0.0001$, effect of cell type $P=0.1376$, interaction between gene type and cell type $P<0.0001$; ${ }^{*}$ MCF-7Ca versus LTLTCa for specific gene, $P<0.0001$; two-way ANOVA). B) LTLTCa and MCF-7Ca cells were treated with vehicle or $0.5 \mu \mathrm{g} / \mathrm{ml}$ actinomycin D for 0 to 16 hours. Total RNA was extracted and HIF-1a mRNA underwent real-time RT-PCR. Results are expressed as least square means of log transformed averages of mRNA expression at various timepoints (trend over time) after normalization to corresponding vehicle-treated samples and analysis by linear mixed effect model, adjusting for experiment, cell line and cell line*time interaction (means \pm SD of $n=6$ independent samples/group; $P<0.001$ for effect of cell line, time, their interaction and experiment). C) LTLTCa cells were treated with vehicle or $100 \mu \mathrm{M} \mathrm{CoCl} 2$ for three hours and then with 100 uM cycloheximide for 0 to 60 minutes. Whole cell protein was extracted and underwent Western blot for HIF-1a and AIB1 protein. Shown are representative blots and overall densitometry results of $n=6$ independent cell samples/group. Densitometry results are expressed as mean fold-change in protein levels compared to vehicle-treated-0 minutes cycloheximide cells after normalization to AIB1 (mean \pm SD of $n=6$ independent cell samples/group; * versus no $\mathrm{CoCl}_{2}-0$ minutes $\mathrm{CHX}, P<0.0001$, one-way ANOVA). ANOVA, analysis of variance; ERa, estrogen receptor alpha; HER2, human epidermal growth factor receptor 2; HIF-1a, hypoxia inducible factor 1 a subunit; $\mathrm{n}$, number; SD, standard deviation. 
file 1: Table S1.1). HIF-1 $\alpha$ mRNA was more abundant in LTLTCa cells than MCF-7Ca cells prior to four hours of actinomycin $\mathrm{D}$ treatment, but it was less by sixteen hours (Figure 2B). Statistical analysis of HIF$1 \alpha$ mRNA expression over time in LTLTCa cells compared to MCF-7Ca cells showed significant effects of time, and cell line, and their interaction $(P<0.001$; linear mixed effect model of time regression analysis). Third, investigation of HIF- $1 \alpha$ protein stability after treatment with the protein synthesis inhibitor cycloheximide with or without the HIF-1 $\alpha$ protein stabilizer $\mathrm{CoCl}_{2}$ [45], demonstrated that after addition of the protein synthesis inhibitor cycloheximide, HIF$1 \alpha$ protein in vehicle-treated LTLTCa cells rapidly degraded within 15 minutes (Figure 1C). In contrast, HIF- $1 \alpha$ expression in $\mathrm{CoCl}_{2}$-treated LTLTCa cells was elevated by $2.8 \pm 0.0$-fold compared to $1.0 \pm 0.3$-fold in vehicle-treated cells $(P<0.0001)$, and did not decrease through 60 minutes of cycloheximide treatment (2- to 2.8 -fold at each time point, $P<0.001$ ) (Figure $1 \mathrm{C}$ ). These protein results are consistent with what is known about the rapid proteosomal degradation of HIF- $1 \alpha$ protein in nonhypoxic cells [44], and the effect of
$\mathrm{CoCl}_{2}$ on $\mathrm{HIF}-1 \alpha$ protein stability [46]. These protein stability results further rule out increased protein stability as the basis for elevated HIF- $1 \alpha$ levels in LTLTCa cells under nonhypoxic conditions.

\section{HER2-activated PI3K/Akt/mTOR pathway regulates HIF-1a expression in LTLTCa cells}

Since LTLTCa cells have significantly higher HER2 protein and mRNA expression compared to MCF-7Ca cells ([47], Figures $1 \mathrm{~A}$ and $2 \mathrm{~A}$ ), this current study sought to determine whether endogenously overexpressed HER2 affects HIF- $1 \alpha$ in LTLTCa cells. To do this, the effects of two types of HER2 inhibitors on HIF- $1 \alpha$ were studied (Figure 3). Lapatinib is a HER2 kinase inhibitor that does not affect HER2 expression but does decrease HER2 activation of downstream kinase pathways (for example, MAPK, PI3K/Akt/mTOR pathway). Trastuzumab is a HER2 monoclonal antibody that decreases HER2 expression and its activation of downstream kinase pathways. As expected, only trastuzumab significantly reduced HER2 protein expression $(0.4 \pm 0.05$ versus $1 \pm 0.2$ vehicletreated), but both lapatinib and trastuzumab inhibited activation of the MAPK $(0.2 \pm 0.1$-fold and $0.3 \pm 0.01$-fold,

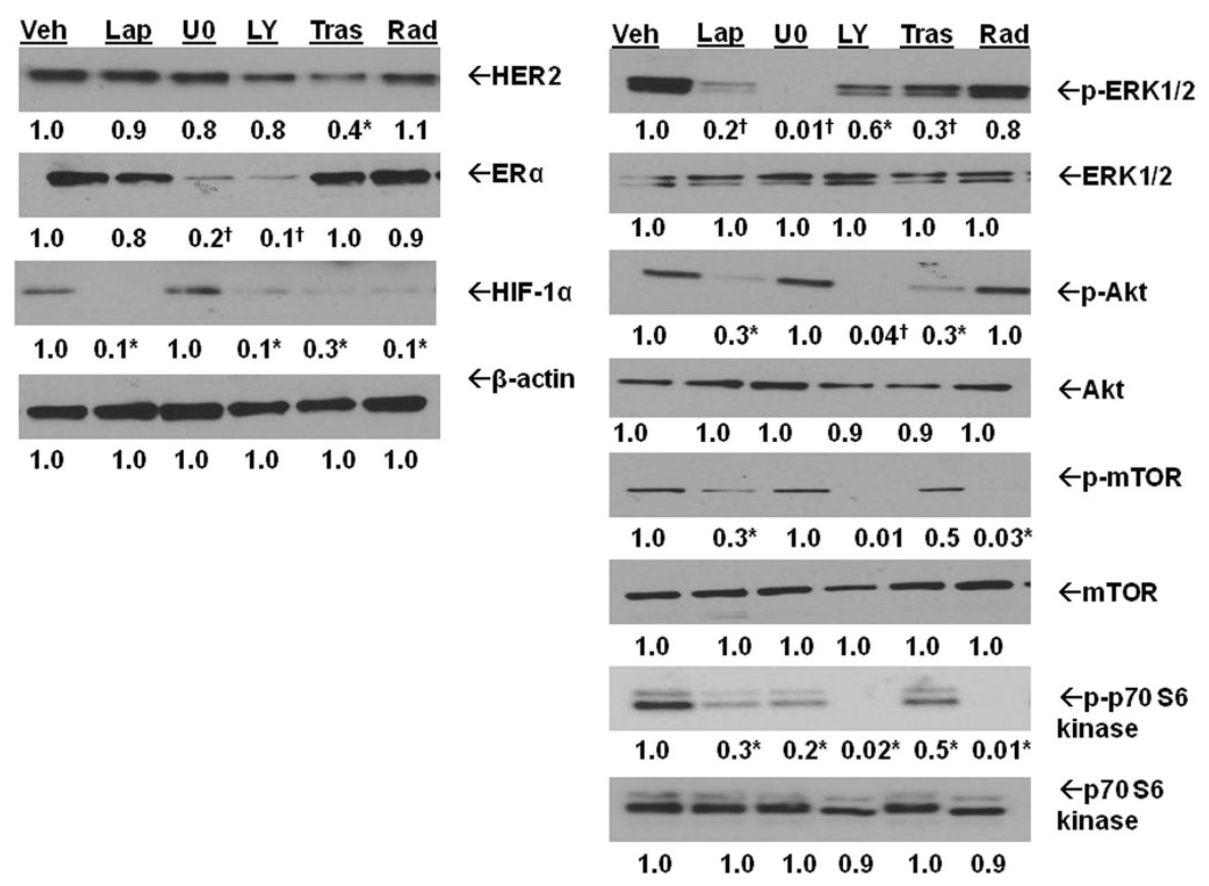

Figure 3 Regulation of HIF-1a protein in LTLTCa cells. A) LTLTCa cells were treated with either vehicle, $1 \mu$ M lapatinib, $20 \mu M$ MAPK pathway inhibitor U0126, 20 MM LY294002 PI3K pathway inhibitor, $500 \mu \mathrm{g} / \mathrm{ml}$ trastuzumab or $100 \mathrm{nM}$ RAD001 for 24 hours. Total protein was extracted and HER2 $(P=0.128)$, phospho- and total-ERK1/2 $(P<0.0001$ for $p$-ERK), phospho- and total-Akt $(P<0.0001$ for $p$-Akt), phospho- and total mTOR $(P=0.0071)$, phospho- and total p70 S6 kinase $(P<0.0001)$, ERa $(P<0.0001)$, HIF-1a $(P=0.0003)$, and $\beta$-actin were analyzed by Western blot. Shown are representative blots and overall densitometry results of $n=6$ independent cell samples/group. Densitometry results are expressed as mean fold-change in protein levels compared to vehicle-treated cells after normalization to $\beta$-actin (mean $\pm S D, n=6$ independent cell samples/group; *versus vehicle, $P<0.05$; $†$ versus vehicle, $P<0.001$, one-way ANOVA). ANOVA, analysis of variance; ERa, estrogen receptor alpha; HER2, human epidermal growth factor receptor 2; HIF-1a, hypoxia inducible factor 1 a subunit; n, number; SD, standard deviation; mTOR, mammalian target of rapamycin. 
respectively, versus $1 \pm 0.2$-fold vehicle-treated of $\mathrm{p}$-ERK1/ $2, \quad P<0.05)$ and $P I 3 K / A k t$ pathways $(0.2 \pm 0.2$-fold and $0.3 \pm 0.08$-fold versus $1 \pm 0.09$-fold vehicle of $\mathrm{p}$-Akt, $P<0.01$ ) (Figure 3 ). Both inhibitors also significantly decreased HIF-1 $\alpha$ protein expression in LTLTCa cells $(0.2 \pm 0.2$-fold and $0.4 \pm 0.2$-fold, respectively, versus of $1 \pm 0.1$-fold vehicle-treated, $P<0.001$ ) (Figure 3 ).

Since both the MAPK and PI3K/Akt/mTOR pathways are activated by HER 2 and known to regulate HIF- $1 \alpha$ expression and activity $[44,48,49]$, the effect of specific inhibition of each pathway on HIF-1 $\alpha$ expression was also studied (Figure 3). As expected, the MAPK inhibitor U0126 effectively decreased p-ERK $1 / 2$ protein expression $(0.01 \pm 0.01$-fold versus $1 \pm 0.2$-fold vehicle-treated, $P<0.001)$, and the PI3K inhibitor LY294002 decreased p-Akt $(0.01 \pm 0.01$-fold versus $1 \pm 0.09$-fold vehicle-treated), downstream Akt target p-mTOR $(0.5 \pm 0.2$-fold versus $1 \pm 0.2$-fold vehicle-treated), downstream mTOR target p-70 S6 kinase $(0.02 \pm 0.02$-fold versus $1 \pm 0.1$-fold vehicletreated). Also as expected, the mTOR inhibitor
Rad001 decreased phosphorylation of mTOR $(0 \pm$ 0.01 versus $1 \pm 0.1$-fold vehicle) and p70 S6 kinase $(0.02 \pm 0.02$-fold versus $0.1 \pm 0.1$-fold vehicle $)$ without affecting upstream Akt (Figure 3). HIF-1 $\alpha$ protein expression was significantly decreased in LTLTCa cells with LY294002 (0.1 \pm 0.1 -fold versus $1 \pm 0.1$-fold vehicle-treated) and Rad001 (0.1 \pm 0.06 -fold versus 1 \pm 0.1 -fold vehicle-treated), but not by U0126. Overall, these results indicate that HER2 activation of the PI3K/Akt/mTOR pathway induces HIF-1 $\alpha$ expression. They also suggest that the HER2activated MAPK pathway in LTLTCa cells has distinct functions from that of the PI3K/Akt/mTOR pathway.

\section{HIF-1a involvement in HER2 regulation of BCRP expression}

As a transcription factor, HIF-1 may be mediating the effects of HER2 on target genes that contribute to the LTLTCa cell phenotype. One such gene may be the breast cancer resistance protein $(B C R P)$, an efflux
A
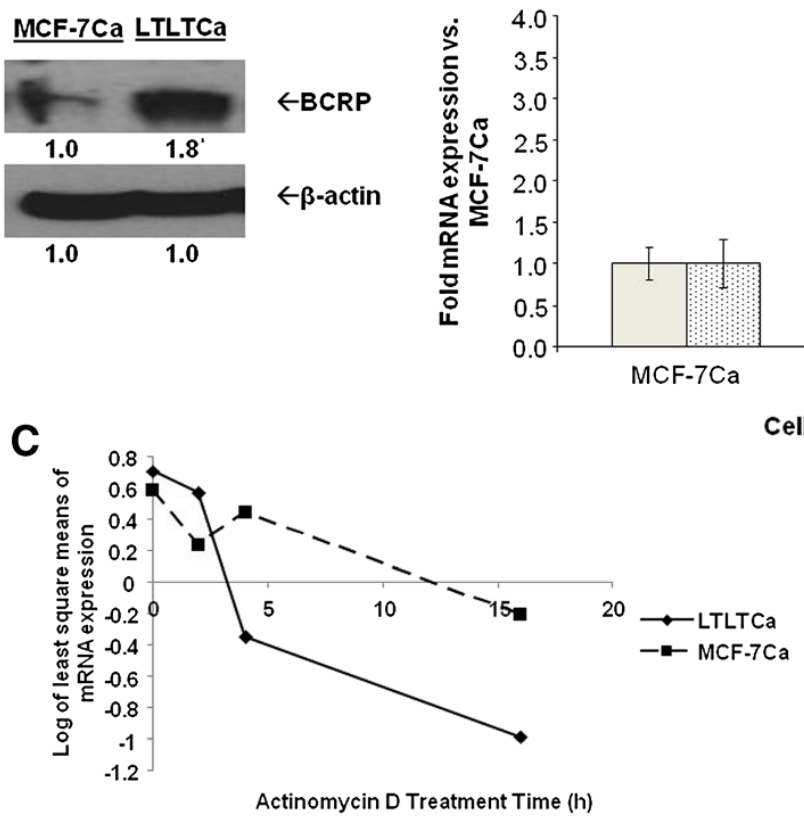

B

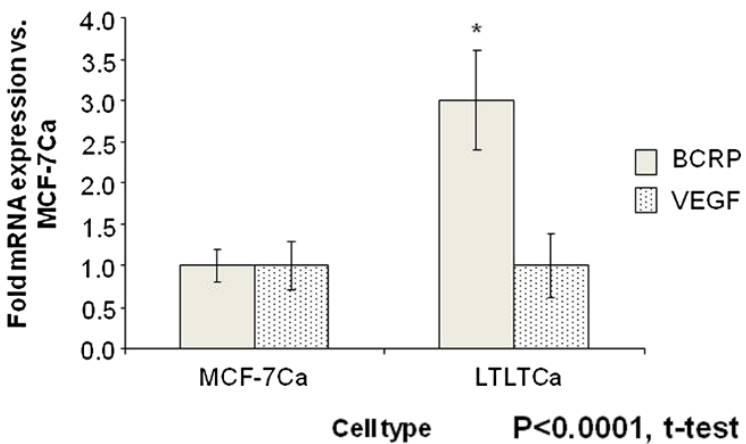

Figure 4 Comparison of BCRP protein and mRNA expression and stability in LTLTCa and MCF-7Ca cells. LTLTCa and parental MCF-7Ca cells were plated and cultured in their respective passage media under normal cell culture (nonhypoxic) conditions. A) Total protein was extracted and BCRP and $\beta$-actin were analyzed by Western blot analysis. Densitometry results are expressed as fold-change in protein levels compared to MCF-7Ca cells after normalization to $\beta$-actin (mean $\pm \mathrm{SD}, \mathrm{n}=6$ independent cell samples/group; *versus MCF-7Ca, $P<0.0001$, two-sided t test). B) Total RNA was extracted and BCRP mRNA, VEGF mRNA and $18 \mathrm{~S}$ rRNA were analyzed by real-time RT-PCR analysis. Results are expressed as the fold-change in mRNA levels compared with MCF-7Ca cells after normalization to $18 \mathrm{~S}$ rRNA (mean $\pm \mathrm{SD}, \mathrm{n}=6$ independent cell samples/group; *versus MCF-7Ca, $P<0.0001$, two-tailed t-test). C) LTLTCa and MCF-7Ca cells were treated with vehicle or $0.5 \mu \mathrm{g} / \mathrm{ml}$ actinomycin D for 0 to 16 hours. Total RNA was extracted and BCRP mRNA was analyzed by real-time RT-PCR. Results are expressed as least square means of log transformed averages of mRNA expression at various timepoints (trend over time) after normalization to corresponding vehicle-treated samples, and analysis by linear mixed effect model adjusting for experiment, cell line, and cell line ${ }^{*}$ time interaction (mean \pm SD of $n=6$ independent cell samples/group; *versus MCF-7Ca; effect of gene type $P=0.0025$, effect of cell type $P=.3749$, interaction between gene type and cell type $P=0.0025$; two-way ANOVA). ANOVA, analysis of variance; BCRP, breast cancer resistant protein; $n$, number; SD, standard deviation; VEGF, vascular endothelial growth factor. 
transporter protein and stem cell marker implicated in cancer cell chemoresistance [50,51]. BCRP is also known to be a HIF-1 target gene [31]. Recently, findings from our laboratory have shown that BCRP protein is overexpressed in LTLTCa cells compared to MCF-7Ca cells and that BCRP is important in stem cell characteristics of LTLTCa (for example, mammosphere formation, side population percentage) [52]. This current study confirms the overexpression of BCRP protein in LTLTCa cells, and further demonstrates that BCRP mRNA expression ( $3 \pm 0.6$-fold versus $1 \pm 0.2$-fold vehicle-treated, $P<0.0001$, one-way ANOVA) is also elevated compared to MCF-7Ca cells (Figure 4A-B). BCRP mRNA stability was also compared between the two cell types. Consistent with findings of others in MCF-7 cells [53], BCRP mRNA is fairly stable through 16 hours of actinomycin D treatment in MCF-7Ca cells (Figure 2C). Overall, BCRP
mRNA in LTLTCa cells was not significantly more stable than in MCF-7Ca (Figure 4C). Statistical analysis of BCRP mRNA expression over time in LTLTCa cells compared to MCF-7Ca cells showed significant effects of time, but not cell line (effect of time $P<0.001$; effect of cell line at $P=0.049$; linear mixed effect model of time regression analysis). Thus, overexpression of BCRP in LTLTCa cells is attributed to increased synthesis at the gene transcription level.

In order to elucidate the factors and pathways involved in regulating BCRP expression, the effects of the HER2 kinase inhibitor lapatinib, HIF-1 $\alpha$ stabilizer $\mathrm{CoCl}_{2}$, and/or specific kinase pathway inhibitors U0126 (MAPK pathway) and LY294002 (PI3K/Akt pathway) on BCRP protein or mRNA expression were assessed (Figure 5A-B). Lapatinib reduced both BCRP protein (0.2-fold versus 1.0 -fold vehicle, $P<0.01)$ and mRNA $(0.6 \pm 0.2$-fold versus 1.0
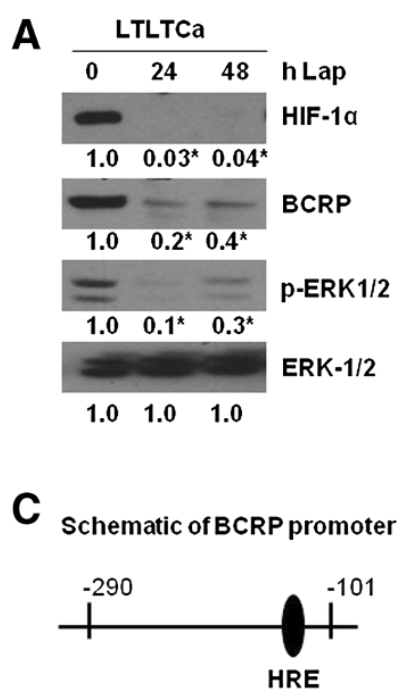
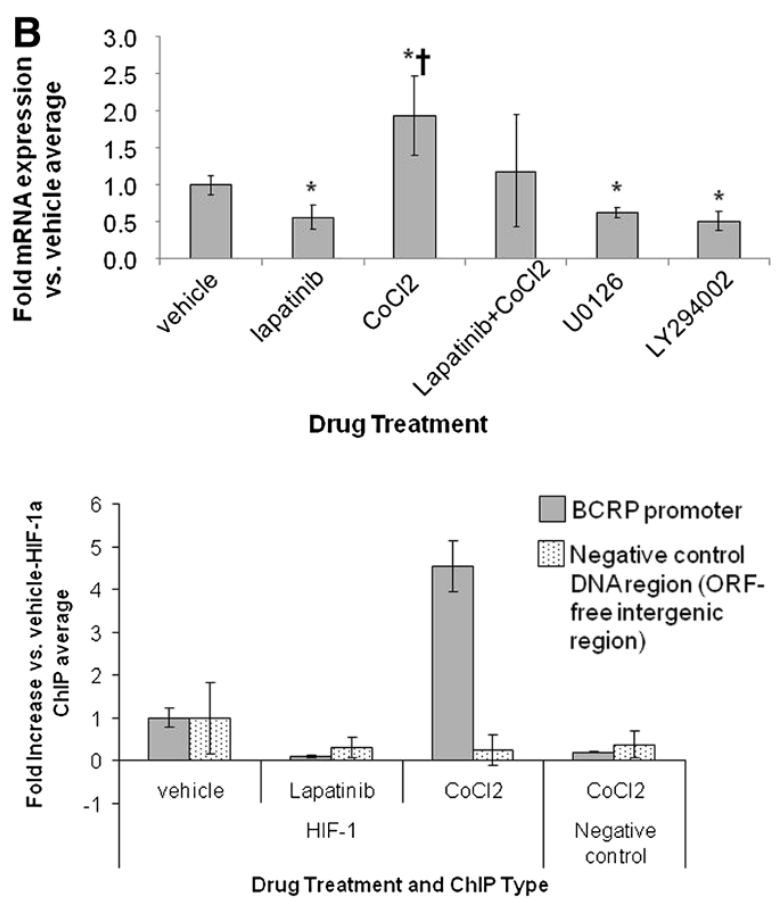

Figure 5 Effect of lapatinib and $\mathrm{CoCl}_{2}$ on BCRP protein and mRNA expression and on HIF-1a binding to the BCRP promoter. A-B), A) LTLTCa cells were treated with $1 \mu \mathrm{M}$ lapatinib for 0 to 48 hours. Total protein was extracted and underwent Western blot for HIF-1a, BCRP, p-ERK1/2, and ERK. Shown are representative blots and overall densitometry results of $n=6$ independent cell samples/group. Densitometry results are expressed as mean fold-change compared to 0 hours after normalization to ERK (mean \pm SD of $n=6$ independent cell samples/group; *versus 0 hours lapatinib; $P=0.0004$ for ERK for HIF-1a, $P=0.0017$ for BCRP, $P=0.0009$ for phospho-ERK1/2, $P=1$ for ERK-1/2; one-way ANOVA). B) Total RNA was extracted and underwent real-time RT-PCR for BCRP mRNA and $18 S$ rRNA. Real-time results are the mean fold-change in mRNA levels compared with vehicle after normalization to $18 \mathrm{~S} r R N A$ (mean \pm SD of $n=6$ independent cell samples/group; *versus vehicle, $P<0.05$; $†$ versus lapatinib, U0126 or LY294002, $P<0.01$; overall $P<0.0001$, one-way ANOVA). C) LTLTCa were treated with vehicle, $1 \mu M$ lapatinib, and/or $100 \mu M$ $\mathrm{CoCl}_{2}$ for 24 hours. Protein-DNA complexes from LTLTCa cells were analyzed by ChIP analysis. Immunoprecipitation was done either with HIF-1a antibody or an equivalent volume of normal mouse serum (negative control). Primers for either the -290 to -101 region of the human BCRP promoter, which contains the HRE to which HIF-1 binds, or ORF-free intergenic region (negative control DNA region) were used for real-time PCR. Results are the mean fold increase compared with vehicle-treated cells after normalization to input samples of each (means $\pm S D, n=6$ independent cells sample/group; *versus vehicle-HIF-1 IP; $P=0.004$ for BCRP promoter, $P=.2972$ for negative control ORF-free intergenic region; one-way ANOVA). ANOVA, analysis of variance; BCRP, breast cancer resistant protein; ChIP, chromatin immunoprecipitation; HIF-1a, hypoxia inducible factor 1 a subunit; n, number; SD, standard deviation. 
\pm .0 .02 -fold vehicle-treated, $P<0.01$, one-way ANOVA) levels in LTLTCa cells. This decrease correlated with lapatinib's inhibitory effects on HIF- $1 \alpha$ and p-ERK $1 / 2$ expression. Inhibition of either the MAPK or PI3K/Akt pathways also resulted in decreased BCRP mRNA levels $(0.7 \pm 0.05$-fold and $0.55 \pm 0.08$-fold versus $1.0 \pm .0 .02$ vehicle-treated, $P<0.01$, respectively; Figure $5 \mathrm{~B}) . \mathrm{CoCl}_{2}$ treatment conversely increased BCRP mRNA in LTLTCa cells. Co-treatment with lapatinib and $\mathrm{CoCl}_{2}$ resulted in BCRP mRNA levels that tended to be intermediate of lapatinib-inhibited and $\mathrm{CoCl}_{2}$-induced levels, but not significantly different from either one and from vehicle (Figure 5B).

Although results in Figure 5A-B suggested that HER2, via the MAPK and PI3K/Akt pathways, and HIF- $1 \alpha$ are both involved in regulating BCRP expression in LTLTCa cells, these expression analyses did not test whether HIF$1 \alpha$ actually mediates the effects of HER 2 on target genes. ChIP analysis was, therefore, performed to determine HIF- $1 \alpha$ binding to the BCRP promoter under basal, nonhypoxic conditions and after lapatinib or $\mathrm{CoCl}_{2}$ treatment.
Real-time PCR analysis of immunoprecipitated DNA after ChIP showed that under basal, nonhypoxic conditions HIF- $1 \alpha$ was bound to a hypoxia-response element (HRE)containing region of the BCRP promoter in LTLTCa cells (Figure $5 \mathrm{C}$ ). $\mathrm{CoCl}_{2}$ significantly increased $\mathrm{HIF}-1 \alpha$ binding to the BCRP promoter, but lapatinib treatment prevented this binding (versus $1 \pm 1$.2-fold vehicle-treated, $P=0.004$, one-way ANOVA). Specificity of immunoprecipitation was confirmed by the lack of immunoprecipitated DNA in the negative IP control samples, as well as on the negative control DNA $(P=0.2972$, one-way ANOVA). In addition, samples in the BCRP promoter PCR (excluding input) amplified at cycles 20 to 30, while samples in the negative control DNA region PCR (excluding input) amplified at cycles 32 to 40 . Correlation between HIF-1 $\alpha$ binding to the BCRP promoter and changes in BCRP mRNA and protein expression in the absence or presence of lapatinib suggests that HER2-regulated HIF-1 is involved in BCRP gene expression in LTLTCa cells.

Such regulation, however, does not appear to be relevant to all known HIF-1 target genes. Vascular endothelial
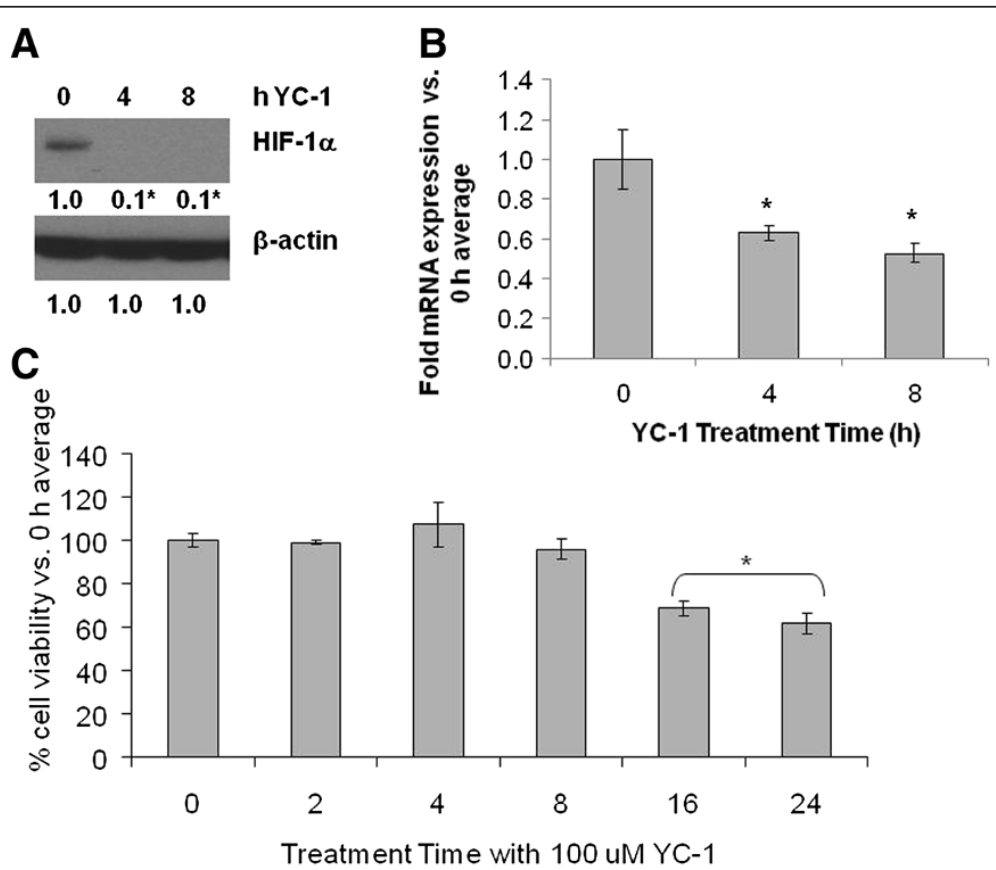

Figure 6 Effect of YC-1 on HIF-1a and BCRP expression and cell viability in LTLTCa cells. LTLTCa cells were treated with $100 \mu \mathrm{M}$ YC-1 for 0 to 24 hours and effects on HIF-1a (A) and BCRP (B) expression and cell viability (C) were determined. A) After 0 to 4 hours of YC-1 treatment, total protein was extracted and HIF-1 $\mathrm{a}$ and $\beta$-actin were analyzed by Western blot analysis. Shown are representative blots and overall densitometry results of $n=6$ independent cell samples/group. Densitometry results are expressed as mean fold-change in protein levels compared to 0 hours after normalization to $\beta$-actin (mean $\pm S D$ of $n=6$ independent cell samples/group; *versus 0 hours $Y C-1, P<0.001$; overall $P<0.0001$, one-way ANOVA). B) After 0 to 8 hours YC-1 treatment, total RNA was extracted and BCRP mRNA and 185 rRNA were analyzed by real-time RT-PCR analysis. Real-time results are expressed as the mean fold-change in mRNA levels compared with vehicle after normalization to $18 \mathrm{~S}$ rRNA (mean $\pm S D, n=6$ independent cell samples/group; *versus 0 hours $Y(-1, P<0.001$; overall $P<0.0001$, one-way ANOVA). C) Viability of cells was measured by MTT assay after 0 to 24 hours treatment with YC-1. Results are expressed as mean percent of 0 hours average (mean $\pm S D, n=4$ independent cell samples/group; *versus 0 hours, $P<0.001 ;$ overall $P<0.0001$, one-way ANOVA). ANOVA, analysis of variance; BCRP, breast cancer resistant protein; HIF-1a, hypoxia inducible factor 1 a subunit; MTT, 3-[4,5-dimethylthiazol-2-yl]-2,5 diphenyl tetrazolium bromide; n, number; SD, standard deviation. 
growth factor (VEGF), another known HIF-1 target gene and important therapeutic target in cancer [17], is not upregulated in LTLTCa cells compared to MCF-7Ca cells (Figure 2B). Also, despite being induced by $\mathrm{CoCl}_{2}$, VEGF mRNA expression was not sensitive to lapatinib (data not shown).

\section{Effect of specific inhibition of HIF-1a on BCRP}

To further support a connection between HIF- $1 \alpha$ and BCRP, HIF-1 $\alpha$ expression in LTLTCa cells was specifically inhibited by either YC-1, a known pharmacological inhibitor of HIF- $1 \alpha[54,55]$ or siRNA. Similar to observations with lapatinib treatment, HIF- $1 \alpha$ protein and BCRP mRNA expression were significantly decreased $(0.1 \pm 0.1$-fold versus $0.1 \pm 0.3$-fold vehicle-treated and $0.5 \pm 0.05$-fold versus $1 \pm 0.15$-fold vehicle treated $P$ $<0.0001$, respectively) in LTLTCa cells within eight hours of $\mathrm{YC}-1$ treatment (Figure 6A-B). This correlated with a $30 \%$ to $40 \%$ decrease in LTLTCa cell viability by 16 and 24 hours, respectively (Figure 6C). Specific inhibition of HIF-1 $\alpha$ expression by siRNAs also significantly decreased both HIF- $1 \alpha$ mRNA (approximately $0.4 \pm 0.04$ fold versus $1 \pm 0.2$-fold negative control siRNA, $P=$ 0.0057 , one-way ANOVA) and protein ( $0.3 \pm 0.1$-fold to $0.03 \pm 0.1$-fold versus $1 \pm 0.05$-fold negative control, $P$ $<0.0001$, one-way ANOVA), as well as BCRP mRNA (0.4to 0.6 -fold versus $1 \pm 0.2$-fold negative control siRNA, $P$ $<0.0001$, one-way ANOVA) expression after 48 hours (Figure 7A-B).
Correlation between HER2, HIF-1a, and BCRP in HER2transfected cells and another Al-resistant cell line

To further confirm the role of HER2 in regulating HIF$1 \alpha$ and BCRP and to determine if ER $\alpha$ is also involved, protein expression in Hc7 cells, ER $\alpha+$ MCF-7 cells transfected with HER2 gene was also studied. Similar to ER $\alpha$-/HER2+ LTLTCa cells, Hc7 cells overexpressed phospho-ERK, HIF- $1 \alpha$ and BCRP protein expression compared to ER $\alpha+/$ HER2-parental MCF-7 cells (Figure 8A). Furthermore, HER2 inhibition by lapatinib decreased HIF- $1 \alpha$ protein levels in Hc7 cells $(0.1 \pm 0.1$-fold versus vehicle, $P<0.0001$; Figure $8 \mathrm{~B})$. Interestingly, inhibition of ER $\alpha$ alone by the ER $\alpha$ antagonist ICI 182,780 also reduced HIF- $1 \alpha$ levels, but its effect on the protein level was significantly less than that of lapatinib alone or lapatinib and ICI182,780 in combination (Figure 8C). Another AI-resistant cell line, exemestane-resistant AC1-ExR breast cancer cells, was also analyzed. Despite retaining ER $\alpha$, AC1-ExR cells also showed higher HER2, HIF- $1 \alpha$ and BCRP protein levels. Overall, these results further indicate that increased HER2 and HER2-activated kinase pathways correlate with increased HIF-1 $\alpha$. They also indicate that while ER $\alpha$ can play a role in regulating HIF-1, as has been suggested by other studies [22], HER2 is likely to be the more important factor in the cells studied.

\section{Functional importance of HIF-1a in LTLTCa cells Effect of HIF-1a inhibition on LTLTCa cells}

Lastly, the functional importance of HIF-1 to the letrozoleresistant cell phenotype was explored. In cancer cells, 


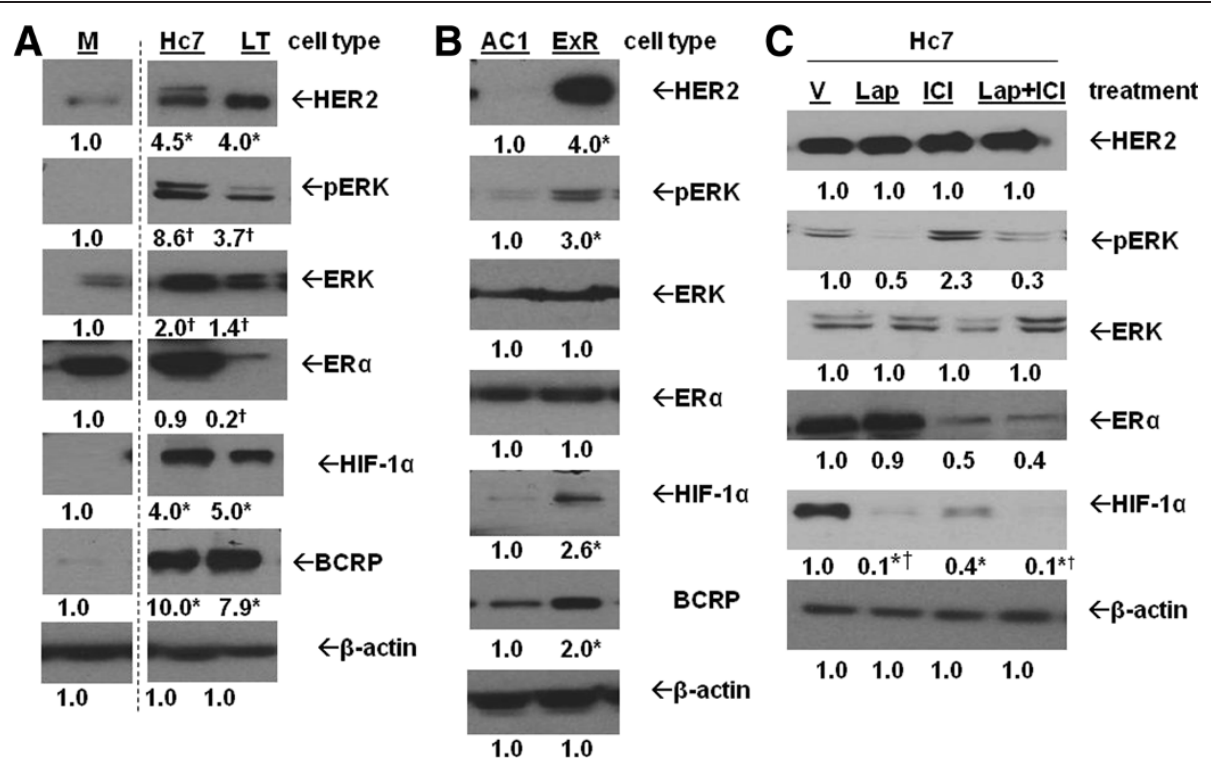

Figure 8 Protein expression in HER2+ cells and exemestane-resistant cells. A) MCF-7Ca (M), HC7 and LTLTCa (LT) cells were plated in their respective passage media. Total protein was extracted and HER2, phosphorylated-and total-ERK, ERa, HIF-1a, BCRP and $\beta$-actin protein were analyzed by Western blot. Shown are representative blots and overall densitometry results of $n=6$ independent cell samples/group. Densitometry results are expressed as mean fold-change compared to MCF-7Ca after normalization to ERK (mean \pm SD of $n=6$ independent cell samples/group; *versus MCF-7Ca, $P<0.05$; + versus MCF-7Ca, $P<0.001$, one-way ANOVA). Dashed lines indicate omitted lane in between $\mathrm{M}$ and $\mathrm{HC7}$ of the same blots. B) AC1 (AC1) and AC1-ExR (ExR) cells were plated in their respective passage media. Total protein was extracted and HER2, phosphorylatedand total-ERK, ERa, HIF-1a and $\beta$-actin protein were analyzed by Western blot. Shown are representative blots and overall densitometry results of $\mathrm{n}=6$ independent cell samples/group. Densitometry results are expressed as mean fold-change compared to vehicle-treated cells after normalization to $\beta$-actin (mean \pm SD of $n=6$ independent cell samples/group; *versus vehicle, $P<0.0001$, two-sided t-test). C) MCF-7/HER2 cells were treated with either vehicle (V), 1 MM lapatinib (Lap), $100 \mathrm{nM} \mathrm{ICI} \mathrm{182,780} \mathrm{(ICI)} \mathrm{or} 1$ MM lapatinib + 100 nM ICI 182,780 (Lap + ICI) for 24 hours. Total protein was extracted and HER2, phospho- and total-ERK1/2, ERa, HIF-1a and $\beta$-actin were analyzed by Western blot. Shown are representative blots and overall densitometry results of $\mathrm{n}=6$ independent cell samples/group. Densitometry results are expressed as mean fold-change compared to vehicle-treated cells after normalization to $\beta$-actin (mean \pm SD of $n=6$ independent cell samples/group; *versus vehicle, $P<0.0001$, one-way ANOVA). ANOVA, analysis of variance; BCRP, breast cancer resistant protein; ERa, estrogen receptor alpha; HER2, human epidermal growth factor receptor 2; HIF-1a, hypoxia inducible factor 1 a subunit; n, number; SD, standard deviation.

hypoxia and HIF-1 are known to be involved in increased cell survival, chemoresistance [56,57], resistance to apoptosis [58] and maintenance of cancer stem cell characteristics $[59,60]$. Previous findings from our laboratory [52] have already demonstrated that letrozole resistance and cancer stem cell characteristics of LTLTCa cells are reduced by inhibition of HER2 and/or BCRP. Although Gilani et al. did not specifically test for the involvement of HIF-1, results of this study combined with those of our current study demonstrating the HER2-HIF-1-BCRP pathway, supports a role for HIF-1 in determining the letrozole-resistant cell phenotype.

To determine the functional significance of HIF-1 in LTLTCa cells, the effect of specific inhibition of HIF- $1 \alpha$ expression by siRNA on mammosphere formation and cell viability was analyzed (Figure 9). Consistent with our previous study [52], LTLTCa cells formed mammospheres (306 mammospheres/20,000 cells \pm 5 ) (Figure 9B), and this was decreased by BCRP siRNA treatment (64 mammospheres/20,000 cells \pm 9; $P<0.001$, one-way ANOVA). HIF-
$1 \alpha$ siRNA treatment similarly decreased mammosphere formation in LTLTCa cells (101 mammospheres/20,000 cells \pm 18 ), while $\mathrm{CoCl}_{2}$ increased formation (500 mammospheres/20,000 cells \pm 20$)$ compared to negative controltreated siRNA $(P<0.001$, one-way ANOVA). These results correlated with the effect of HIF- $1 \alpha$ inhibition on other genes. HIF- $1 \alpha$ siRNA treatment decreased BCRP mRNA $(P=0.0377$, one-way ANOVA), as well as expression of GAPDH [61] $(P=0.0058$, one-way ANOVA $)$, another known HIF-1 target gene, and BMI-1 ( $P=0.0214$, one-way ANOVA), another stem cell marker [62] (Figure 9A). HIF$1 \alpha$ siRNA treatment also significantly decreased LTLTCa cell viability $(P<0.0001$, one-way ANOVA) in the presence of increasing concentrations of letrozole (Figure $9 \mathrm{C}$ ).

\section{Effect of HIF-1a upregulation on MCF-7Ca cells}

To further confirm the physiological role of HIF-1 and $\mathrm{BCRP}$, converse experiments were done to investigate whether MCF-7Ca cells could become more letrozoleresistant with increased $\mathrm{HIF}-1 \alpha . \mathrm{CoCl}_{2}$ was used to 

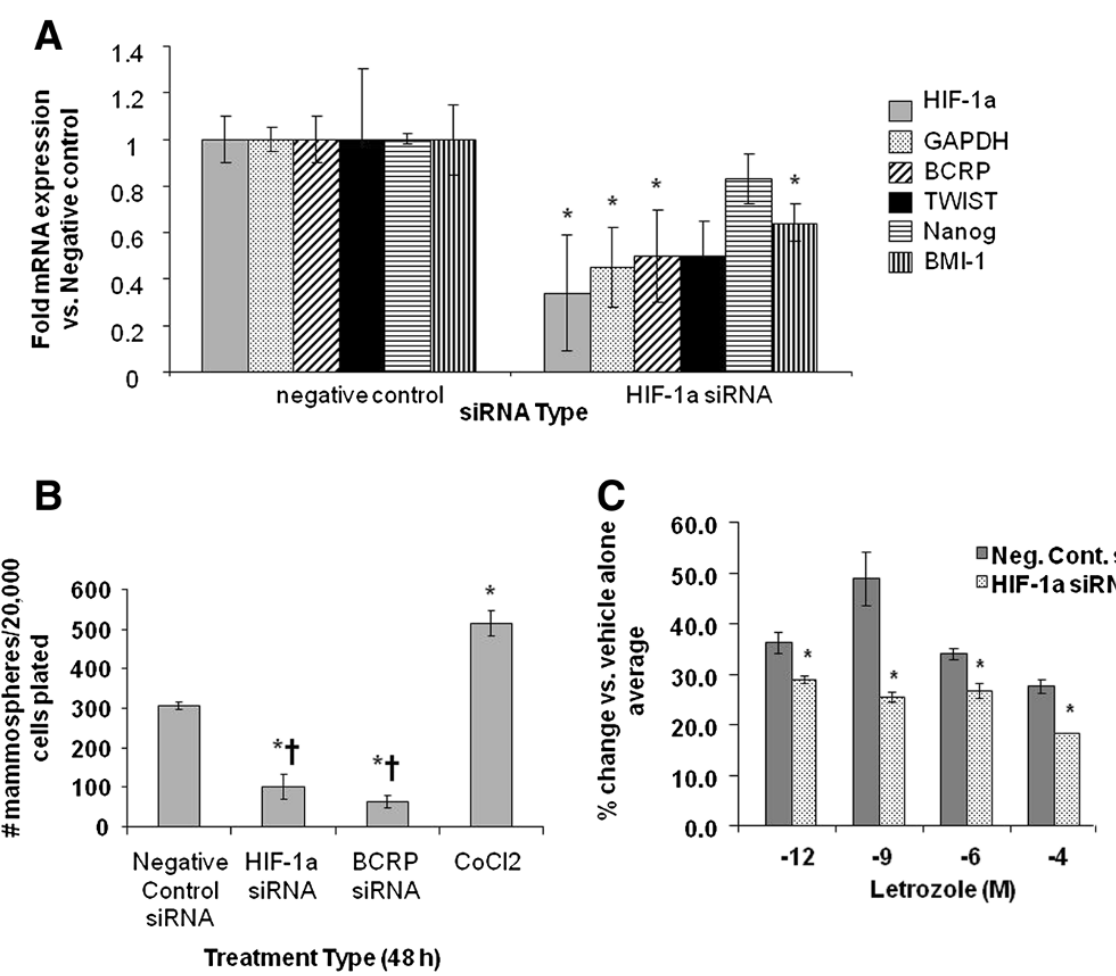

Figure 9 Effect of HIF-1a and/or BCRP siRNA on mammosphere formation and cell proliferation in LTLTCa cells. A) LTLTCa cells were treated with either negative control siRNA or HIF-1a siRNA for 48 hours. Total mRNA was extracted and HIF-1a, BCRP, GAPDH, Nanog, BMI-1 and TWIST mRNA, and $18 \mathrm{~S}$ rRNA were analyzed by real-time RT-PCR. Real-time results are expressed as the fold-change in mRNA levels compared with negative control after normalization to $18 \mathrm{~S}$ rRNA (mean \pm SD, $n=6$ independent cell samples/group; ${ }^{*}$ versus vehicle; $P=0.0 .132 \mathrm{HIF}-1 ; P=0.0058$ GAPDH, $P=0.0377$ BCRP, $P=0.0612$ TWIST, $P=0.058$ Nanog, $P=0.0214$ BMI- 1 ; two-sided t-test). B) LTLTCa cells were plated in passage media and then treated with negative control siRNA, HIF-1a siRNA, BCRP siRNA, or $100 \mu \mathrm{M} \mathrm{CoCl}$, for 48 hours. Cells were then collected and resuspended in mammosphere media on low-attachment cell culture wells. Results are expressed as number of mammospheres counted per 20,000 cells plated (mean $\pm \mathrm{SD}, \mathrm{n}=6$ independent cell samples/group; *versus negative control, $P<0.001$; $†$ versus $\mathrm{CoCl}_{2}, P<0.001$; overall $P<0.0001$, one-way ANOVA). BCRP siRNA confirmed to decrease BCRP expression (0.35- and 0.15 -fold versus negative control, $P<0.01$, one-way ANOVA; data not shown). C) Viability of the cells was measured by the MTT assay after 48 hours treatment with negative control or HIF-1 alpha siRNA and subsequently 6 day treatment with increasing doses of letrozole. Results are expressed as percent of $0 \mu \mathrm{M}$ letrozole (vehicle) (mean $\pm \mathrm{SD}, \mathrm{n}=4$ independent cell samples/ group; *versus 0 MM letrozole, $P<0.001$; overall $P<0.0001$ one way ANOVA). ANOVA, analysis of variance; BCRP, breast cancer resistant protein; HIF-1a, hypoxia inducible factor 1 a subunit; MTT, 3-[4,5-dimethylthiazol-2-yl]-2,5 diphenyl tetrazolium bromide; n, number; SD, standard deviation.

increase HIF-1 $\alpha$ expression in MCF-7Ca cells and the efficacy of $\mathrm{CoCl}_{2}$ was confirmed by Western blot analysis and RT-PCR. Within 24 hours of $\mathrm{CoCl}_{2}$ treatment, HIF$1 \alpha$ protein and BCRP mRNA and protein expression were increased in MCF-7Ca cells (Figure 10A-B). Cell viability experiments in the presence of increasing concentrations of letrozole were then performed $(P<0.0001$, one-way ANOVA). Consistent with previous findings from our laboratory [12], MCF-7Ca cells not treated with $\mathrm{CoCl}_{2}$ were sensitive to the growth inhibitory effects of letrozole (Figure 10C). Additional treatment of MCF-7Ca cells with $\mathrm{CoCl}_{2}$ significantly increased their resistance to letrozole. The effects of $\mathrm{CoCl}_{2}$ were attributable to HIF-1, as co-treatment of MCF-7Ca cells with $\mathrm{CoCl}_{2}$ and HIF- $1 \alpha$ siRNA returned their sensitivity to letrozole. Overall, the physiological experiments on LTLTCa and MCF-7Ca cells indicate that HIF-1 is likely involved in both cancer stem cell characteristics and cell viability.

\section{Discussion}

Prior to this study, AI resistance was associated with increased dependence on growth factors and decreased dependence on ER $\alpha$. However, the role that such molecular changes play in AI resistance and the mechanism by which they elicit their effects were not known. Novel results from this study demonstrated that nonhypoxic expression of HIF-1 mediates HER2's effects on letrozole-resistance. Specifically, the HER2-activated PI3K/Akt pathway increases HIF- $1 \alpha$ protein synthesis in LTLTCa cells. HIF- $1 \alpha$, in turn, upregulates expression of BCRP and other genes and contributes to letrozole resistance and stem cell characteristics of LTLTCa cells. 

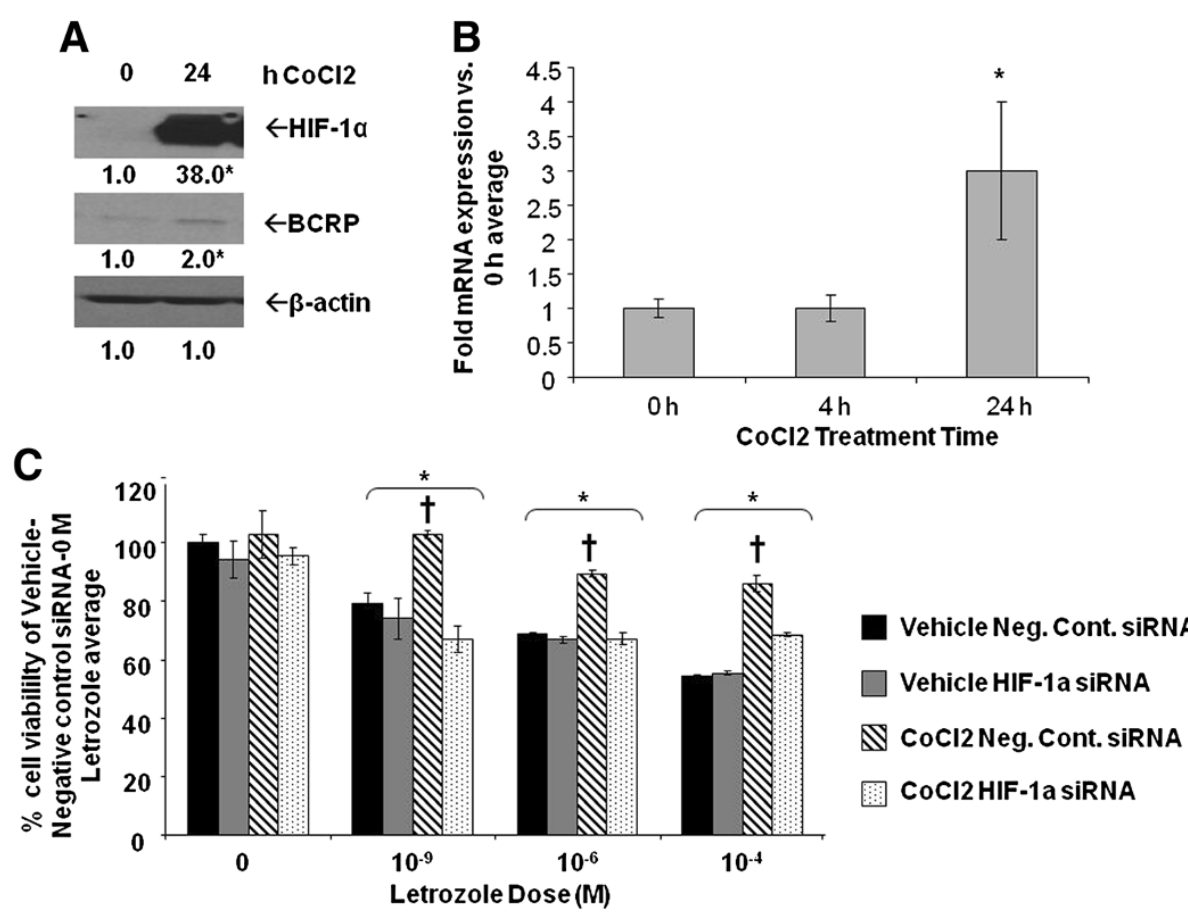

Figure 10 Effect of $\mathrm{CoCl}_{2}$ on MCF-7Ca protein expression and cell viability. A-B, MCF-7Ca cells were incubated in steroid-free media and then treated with $100 \mu \mathrm{M} \mathrm{CoCl}$ for 0 to 24 hours. A) Total protein was extracted and HIF-1a, BCRP, and $\beta$-actin were analyzed by Western blot analysis. Shown are representative blots and overall densitometry results of $n=6$ independent cell samples/group. Densitometry results are expressed as mean fold-change in protein levels compared to 0 hours after normalization to $\beta$-actin (mean \pm SD of $n=4$ independent cell samples/group, *versus 0 hours; $P=0.0005$ for HIF-1a; $P=0.0065$ for BCRP, two-sided t-test). B) Total RNA was extracted and BCRP mRNA and 185 rRNA were analyzed by real-time RT-PCR analysis. Results are expressed as the mean fold-change in mRNA levels compared with 0 hours after normalization to $18 \mathrm{~S} r R N A$ (mean $\pm \mathrm{SD}, \mathrm{n}=4$ independent cell samples/group; *versus 0 hours, $P<0.001$; overall $P=0.0002$, one-way ANOVA). C) Viability of cells was measured by MTT assay after five days of treatment with increasing doses of letrozole following 48 hours pre-treatment with or without $100 \mu \mathrm{M} \mathrm{CoCl}$ and HIF-1a siRNA. Results are expressed as mean percent of $0 \mu \mathrm{M}$ letrozole-without $\mathrm{CoCl}_{2}$-with negative control siRNA (mean \pm SD of $n=6$ independent samples/group; *versus vehicle-negative control siRNA-0 $\mu \mathrm{M}$ letrozole, $P<0.001$; $†$ versus vehicle-HIF-1a siRNA and $\mathrm{CoCl}_{2}-\mathrm{HIF}-1 \mathrm{a}$ siRNA; effect of letrozole $P<0.0001$, effect of pre-treatment (vehicle/ $\mathrm{CoCl}_{2}$ and negative control siRNA/HIF-1a siRNA) $P<0.0001$, interaction between letrozole dose and pre-treatment $P<0.0001$; two-way ANOVA). ANOVA, analysis of variance; BCRP, breast cancer resistant protein; HIF-1a, hypoxia inducible factor 1 a subunit; MTT, 3-[4,5-dimethylthiazol-2-yl]-2,5 diphenyl tetrazolium bromide; n, number; $\mathrm{SD}$, standard deviation.

Nonhypoxic regulation of HIF-1 expression and activity in LTLTCa cells is due to the HER2-activated PI3K/ Akt/mTOR pathway. This is consistent with findings by others indicating hypoxia independent upregulation of HIF- $1 \alpha$ in cancer cells by loss of function of tumor suppressor genes and gain of function of oncogenes [27]. The oncogene HER2/neu, in particular, has been previously associated with nonhypoxic HIF-1 [24,25]. Laughner et al. and Li et al. have demonstrated that transfection of HER2 into NIH/3 T3 cells or activation of HER2 in MCF-7 cells led to activation of the PI3K/Akt pathway, and the subsequent increased HIF-1 expression via protein synthesis and HIF-1 transcriptional activity. Previous studies have also demonstrated the importance of mTOR $[48,49]$. In addition, $\mathrm{mTOR}$ has been explored in two randomized trials (BOLERO-2 and TAMRAD) as a potential therapeutic target for overcoming endocrine therapy resistance [63]. Our current study provides evidence that this HER2-
PI3K/Akt-mTOR-HIF-1 signaling mechanism can indeed occur endogenously in HER2+ cells (Figures 3, 4, and 8), leads to upregulation of BCRP (Figure 2), and has physiological relevance as well as potential clinical implications (for example, AI resistance; Figures 9 and 10).

Despite providing evidence that HER2 activation of the PI3K/Akt-mTOR pathway regulates HIF-1 $\alpha$, this study cannot completely exclude the involvement of ER $\alpha$ or the MAPK pathway. In addition to overexpressing HER2, LTLTCa cells also have decreased expression of ER $\alpha$ (Figure 3). It is possible that ER $\alpha$ can also regulate nonhypoxic HIF-1 $\alpha$ expression in LTLTCa cells. Indeed, ER $\alpha-$ and HIF-1-mediated signaling pathways are known to interact antagonistically $[18,19]$ and cooperatively [20-23]. Although this current study did not directly investigate ER $\alpha$ 's role, the overexpression of HIF- $1 \alpha$ observed in both $\mathrm{ER} \alpha+(\mathrm{Hc} 7$ and Ac1-ExR) and ER $\alpha$ - (LTLTCa) HER2+ breast cancer cell lines, suggests that ER $\alpha$ status may not 
affect HER2 regulation of non-hypoxic HIF-1 $\alpha$ levels. With regard to the MAPK pathway, inhibition of this pathway did not affect HIF-1 $\alpha$ expression in LTLTCa cells, but it did decrease BCRP mRNA expression under basal, nonhypoxic conditions. It is possible that the MAPK pathway is involved in phosphorylation of HIF- $1 \alpha$ rather than its synthesis. Previous studies have shown that MAPK pathwaymediated phosphorylation of HIF-1 $\alpha$ occurs under nonhypoxic conditions and can increase HIF-1 $\alpha$ expression and transcriptional activity $[64,65]$. These results could also indicate the MAPK and PI3K/Akt pathways have very distinct functions in AI-resistant breast cancer cells, regulating different subsets of genes. For example, the MAPK pathway may be involved in HER2 regulation of genes that require activation by phosphorylated ER $\alpha^{\text {Ser118. }}$. In contrast, the PI3K/Akt pathway may be involved in HER2 regulation of genes that require HIF-1.

Inherent upregulation of HIF- $1 \alpha$ protein expression under nonhypoxic conditions is another novel finding in AI-resistant breast cancer. There is precedence for associating HIF-1 expression with drug resistance in different cancer cell types, including chronic myeloid leukemia cells [66], gastric cancer cells [67], non-small cell lung cancer cells [68], and even breast cancer cells [58]. However, these previous cases involved hypoxiainduced, HIF-1 $\alpha$ rather than the non-hypoxic HIF-1. Our findings are also consistent with previous clinical evidence that HIF- $1 \alpha$ is associated with letrozole resistance. Generali et al. demonstrated that increased pMAPK and HIF- $1 \alpha$ protein expression were significant determinants of primary letrozole resistance in breast cancer patients. In contrast, increased $\mathrm{ER} \alpha$ and decreased p-MAPK were significant determinants of response to letrozole treatment [56]. The protein expression patterns observed by Generali et al. are similar to what is observed in letrozole-resistant LTLTCa and sensitive MCF-7Ca cells, respectively (Figures 3 and 6). Although these clinical findings involve de novo letrozole resistance, they still correlate with, and likely pertain to, our laboratory's results on acquired letrozole resistance. These results combined suggest that HIF-1 is involved in both de novo and acquired AI resistance and, therefore, could be therapeutically targeted to prevent and treat resistance to letrozole and the other AIs.

Lastly, this study indicates that HIF-1 may contribute to letrozole resistance by mediating the effects of HER2 on target genes, such as BCRP. Previous findings by our laboratory had implicated HER2 and BCRP in resistance to the growth inhibitory effects of letrozole and to maintenance of stem cell characteristics in letrozole-resistant breast cancer, and had demonstrated that its expression was dependent on HER2 [35,52], but it was unclear until now how HER2 regulated BCRP. Moreover, HIF-1 may mediate the effects of HER2 on many other genes. Besides, BCRP, other known HIF-1 target genes that may serve as markers of letrozole resistance include: 1) cancer stem cell maintenance markers (Oct-4, kit ligand, JARID1B); 2) epithelial-mesenchymal-transition (EMT) markers (Snail, vimentin); and 3) invasion markers (c-Met, endothelin 1, fibronectin, $M M P-2$ and -4) [27,69]. Interestingly, another known HIF-1 target gene, VEGF, was not upregulated in LTLTCa cells compared to MCF-7Ca cells. It is possible that nonhypoxic HIF-1 expression has different levels of influence on different HIF-1 target genes, particularly

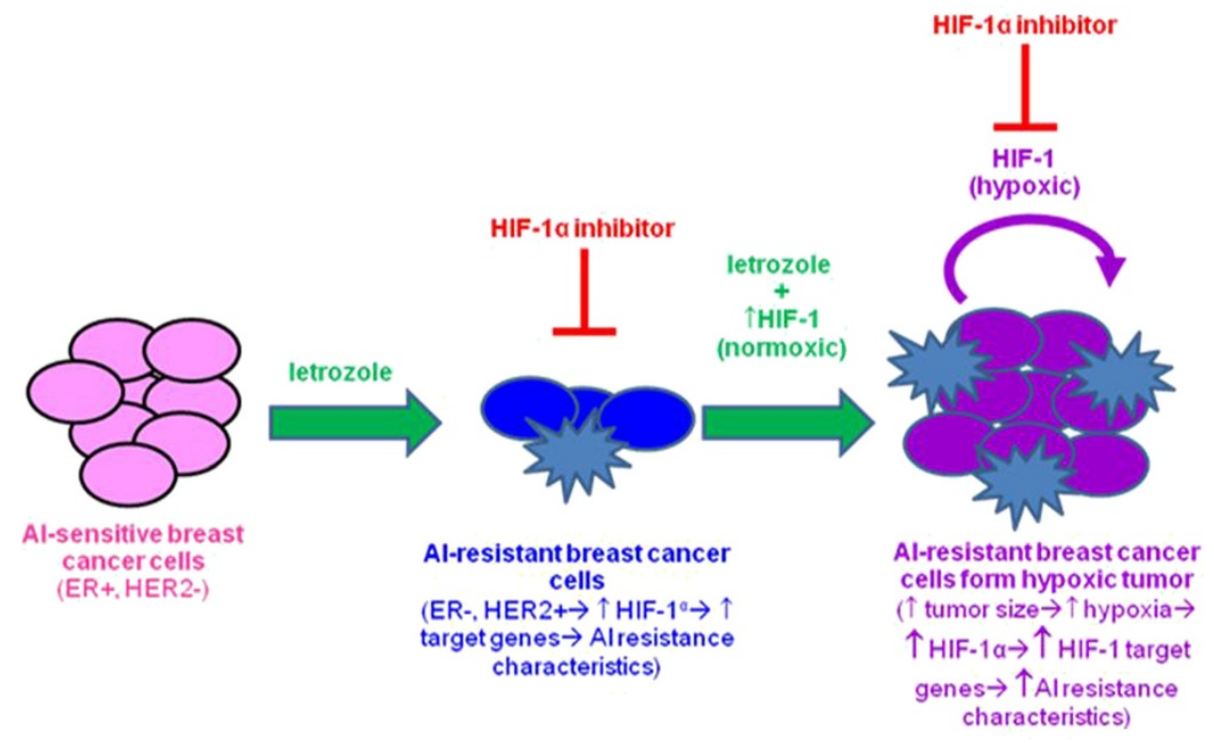

Figure 11 Proposed model of regulation and role of HIF-1a in Al resistant breast cancer. 
those that can be regulated by multiple transcription factors. Indeed BCRP and VEGF both are known to be regulated by additional transcription factors, such as $\mathrm{ER} \alpha[22,70]$.

\section{Conclusions}

Overall, this study provides novel evidence that nonhypoxic HIF- $1 \alpha$ is inherently expressed in AI-resistant cells, upregulated by HER2-PI3K/Akt-mTOR pathway and is an important factor in letrozole-resistant breast cancer cells, regulating target genes such as BCRP and regulating $\mathrm{AI}$ responsiveness and cancer stem cell characteristic expression. Thus, HIF- $1 \alpha$ could be used as a diagnostic marker and/or therapeutic target. Based on this, a proposed model of acquired AI-resistance may involve the following scenario: under non-hypoxic conditions, when the breast cancer cell population and tumor size have been reduced by letrozole treatment and prior to significant tumor hypoxia, a switch from ER $\alpha$ - to growth factor (for example, HER2)-mediated signaling occurs via PI3K/Akt and mTOR, which leads to increased HIF-1 $\alpha$ expression and activation of HIF-1 target genes (for example, $B C R P$ ) that contribute to AI resistance (Figure 11). Consequently, inhibition of HIF-1 expression and/or activity would prolong cancer cell sensitivity to AIs and prevent recurrence and metastasis. Indeed, a number of anti-cancer drugs in clinical use are also known to inhibit HIF-1 [27]. They include HER2 inhibitor, trastuzumab [24] and lapatinib. Furthermore, as demonstrated in this study that HIF-1 is regulated mainly via the PI3K/Akt/ mTOR pathway, inhibition of the downstream affecter of this pathway using mTOR inhibitors, such as rapamycin, temsirolimus/CCI-779 and everolimus/RAD-001, can also be considered [24,71-73]. There is also EZN-2968, a specific HIF- $1 \alpha$ mRNA inhibitor, shown to reduce cancer cell viability and xenograft tumor growth, which is currently under phase I clinical trial [74]. Any of these anti-cancer drugs could now potentially, based on the evidence provided by this study, be applied to the prevention and treatment of AI-resistant breast cancer.

\section{Additional file}

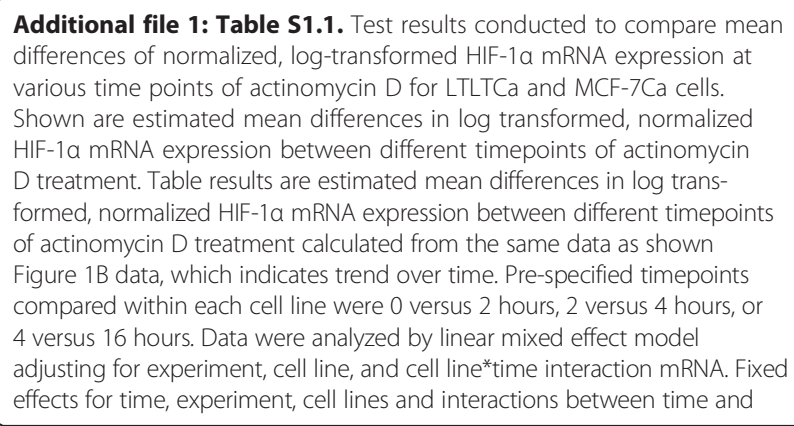

cell lines were determined (means \pm SD of $\mathrm{n}=6$ independent samples/ group; $P<0.001$ for effect of cell line, time, their interaction and experiment). NS, not significant, $P>0.05$. Table S1.2. Test results conducted to compare mean differences of normalized, log-transformed BCRP mRNA expression at various time points of actinomycin D for both LTLTCa and MCF-7Ca cells. Table results are estimated mean differences in log transformed, normalized BCRP mRNA expression between different timepoints of actinomycin D treatment calculated from the same data as shown in Figure $2 \mathrm{C}$. Prespecified timepoints compared within each cell line were 0 versus 2 hours, 2 versus 4 hours, or 4 versus 16 hours. Data were analyzed by linear mixed effect model adjusting for experiment, cell line, and cell line*time interaction mRNA. Fixed effects for time, experiment, cell lines and interactions between time and cell lines were determined (means $\pm S D$ of $n=6$ independent samples/group; $P<0.001$ for effect of time and cell line*time interaction). NS, not significant, $P>0.05$.

\section{Abbreviations}

AC1: MCF-7 cells transfected with the aromatase gene by the laboratory of Dr. Brodie; AC1-ExR: long-term exemestane treated AC1 cells; Al: aromatase inhibitor; Akt: also known as protein kinase B; ANOVA: analysis of variance; BCRP: breast cancer resistance protein; CDT: charcoal-dextran treated; ChIP: chromatin immunoprecipitation; (D)MEM: (Dulbecco's) modified Eagle's medium; EGFR: epidermal growth factor receptor; ERa: estrogen receptor alpha; FBS: fetal bovine serum; HC7: MCF-7 cells transfected with HER2 gene by the laboratory of Dr. Brodie; HER2: human epidermal growth factor receptor 2; HIF-1: hypoxia inducible factor 1; HIF-1a: hypoxia inducible factor 1 a subunit; HRE: hypoxia-response element; LTLTCa: long-term letrozole treated MCF-7Ca cells; MAPK: mitogen-activated protein kinase; MCF-

7Ca: MCF-7 cells transfected with the aromatase gene by the laboratory of Dr. Chen; mTOR: mammalian target of rapamycin; PBS: phosphate-buffered saline; PI3K: phosphatidylinositide 3-kinase; PRF: phenol red-free; ORF: open reading frame; siRNA: small interfering RNA; RT-PCR: reverse transcriptasepolymerase chain reaction; VEGF: vascular endothelial growth factor.

\section{Competing interests}

The authors declare that they have no competing interests.

\section{Authors' contributions}

AK conceived of and designed the study, performed all experiments, and drafted the manuscript. RG participated in RT-PCR in Figure $1 \mathrm{~A}$ and western blot 1B. AS participated in densitometry analysis of Figure $3 \mathrm{~A}$ and helped to draft the manuscript. SC coordinated obtaining lapatinib and trastuzumab and participated in discussions of study design. GS participated in the analysis and interpretation of Western blot data for Figures 3, 4, and 8 and statistical analyses for Figures 1B and 2C. PS participated in the mammosphere assay and selection of cancer stem cell markers in Figure 9A. OG performed statistical analyses for Figures $1 B$ and 2 C. SK performed statistical analyses for Figures $1 B$ and $2 \mathrm{C}$. $\mathrm{AB}$ participated in the design of the study, interpretation of all results, and the critical review and revision of the manuscript. All authors read and approved final manuscript.

\section{Acknowledgements}

Funding for this study was provided by the Department of Defense Breast Cancer Research Program Postdoctoral Award (BC1039031).

\section{Author details}

${ }^{1}$ Department of Pharmacology and Experimental Therapeutics, University of Maryland, Baltimore, MD 21201, USA. ${ }^{2}$ Department of Medicine, University of Maryland, Baltimore, MD 21201, USA. ${ }^{3}$ School of Medicine, University of Maryland Marlene and Stewart Greenebaum Cancer Center, Baltimore, MD 21201, USA. ${ }^{4}$ Division of Biostatistics and Bioinformatics Department of Epidemiology and Public Health, University of Maryland, Baltimore, MD 21201, USA. ${ }^{5}$ Department of Biology, Loyola University Maryland, Baltimore, MD 21210, USA. ${ }^{6}$ Department of Pharmacology and Experimental

Therapeutics, University of Maryland School of Medicine, Health Science Facilities, Room 580G, 685 West Baltimore Street, Baltimore, MD 21201, USA.

Received: 23 October 2012 Accepted: 2 January 2014

Published: 29 January 2014 


\section{References}

1. United States Cancer Statistics: 1999-2008 Incidence and Mortality Webbased Report. [http://www.cdc.gov/uscs.]

2. Chumsri S, Howes T, Bao T, Sabnis G, Brodie A: Aromatase, aromatase inhibitors, and breast cancer. J Steroid Biochem Mol Biol 2011, 125:13-22.

3. Santen RJ, Brodie H, Simpson ER, Siiteri PK, Brodie A: History of aromatase: saga of an important biological mediator and therapeutic target. Endocr Rev 2009, 30:343-375.

4. Nabholtz JM, Mouret-Reynier MA, Durando X, Van Praagh I, Al-Sukhun S, Ferriere JP, Chollet P: Comparative review of anastrozole, letrozole and exemestane in the management of early breast cancer. Expert Opin Pharmacother 2009, 10:1435-1447.

5. Dowsett M, Cuzick J, Ingle J, Coates A, Forbes J, Bliss J, Buyse M, Baum M, Buzdar A, Colleoni M, Coombes C, Snowdon C, Gnant M, Jakesz R, Kaufmann M, Boccardo F, Godwin J, Davies C, Peto R: Meta-analysis of breast cancer outcomes in adjuvant trials of aromatase inhibitors versus tamoxifen. J Clin Oncol 2010, 28:509-518.

6. Winer EP, Hudis C, Burstein HJ, Wolff AC, Pritchard Kl, Ingle JN, Chlebowski RT, Gelber R, Edge SB, Gralow J, Cobleigh MA, Mamounas EP, Goldstein LJ, Whelan TJ, Powles TJ, Bryant J, Perkins C, Perotti J, Braun S, Langer AS, Browman GP, Somerfield MR: American Society of Clinical Oncology technology assessment on the use of aromatase inhibitors as adjuvant therapy for postmenopausal women with hormone receptor-positive breast cancer: status report 2004. J Clin Oncol 2005, 23:619-629.

7. Miller WR, Larionov AA: Understanding the mechanisms of aromatase inhibitor resistance. Breast Cancer Res 2012, 14:201.

8. Kubo M, Kanaya N, Petrossian K, Ye J, Warden C, Liu Z, Nishimura R, Osako T, Okido M, Shimada K, Takahashi M, Chu P, Yuan YC, Chen S: Inhibition of the proliferation of acquired aromatase inhibitor-resistant breast cancer cells by histone deacetylase inhibitor LBH589 (panobinostat). Breast Cancer Res Treat 2013, 137:93-107.

9. Sabnis $\mathrm{G}$, Brodie A: Adaptive changes results in activation of alternate signaling pathways and resistance to aromatase inhibitor resistance. Mol Cell Endocrinol, 340:142-147.

10. Johnston SR, Martin LA, Leary A, Head J, Dowsett M: Clinical strategies for rationale combinations of aromatase inhibitors with novel therapies for breast cancer. J Steroid Biochem Mol Biol 2007, 106:180-186.

11. Macedo LF, Sabnis GJ, Goloubeva OG, Brodie A: Combination of anastrozole with fulvestrant in the intratumoral aromatase xenograft model. Cancer Res 2008, 68:3516-3522.

12. Sabnis G, Schayowitz A, Goloubeva O, Macedo L, Brodie A: Trastuzumab reverses letrozole resistance and amplifies the sensitivity of breast cancer cells to estrogen. Cancer Res 2009, 69:1416-1428.

13. Brodie A, Macedo L, Sabnis G: Aromatase resistance mechanisms in model systems in vivo. J Steroid Biochem Mol Biol 2010, 118:283-287.

14. Schwartzberg LS, Franco SX, Florance A, O'Rourke L, Maltzman J, Johnston S: Lapatinib plus letrozole as first-line therapy for HER-2+ hormone receptor-positive metastatic breast cancer. Oncologist 2010, 15:122-129.

15. Hynes NE, Lane HA: ERBB receptors and cancer: the complexity of targeted inhibitors. Nat Rev Cancer 2005, 5:341-354.

16. Mukohara T: Mechanisms of resistance to anti-human epidermal growth factor receptor 2 agents in breast cancer. Cancer Sci 2011, 102:1-8.

17. Semenza GL: Targeting HIF-1 for cancer therapy. Nat Rev Cancer 2003, 3:721-732.

18. Cho J, Kim D, Lee S, Lee Y: Cobalt chloride-induced estrogen receptor alpha down-regulation involves hypoxia-inducible factor-1alpha in MCF-7 human breast cancer cells. Mol Endocrinol (Baltimore, Md) 2005, 19:1191-1199.

19. Mukundan H, Kanagy NL, Resta TC: 17-beta estradiol attenuates hypoxic induction of HIF-1alpha and erythropoietin in Hep3B cells. J CardiovasC Pharmacol 2004, 44:93-100.

20. Kazi AA, Jones JM, Koos RD: Chromatin immunoprecipitation analysis of gene expression in the rat uterus in vivo: estrogen-induced recruitment of both estrogen receptor alpha and hypoxia-inducible factor 1 to the vascular endothelial growth factor promoter. Mol Endocrinol (Baltimore, Md) 2005, 19:2006-2019.

21. Cho J, Bahn JJ, Park M, Ahn W, Lee YJ: Hypoxic activation of unoccupied estrogen-receptor-alpha is mediated by hypoxia-inducible factor-1 alpha. J Steroid Biochem Mol Biol 2006, 100:18-23.

22. Kazi AA, Koos RD: Estrogen-induced activation of hypoxia-inducible factor-1alpha, vascular endothelial growth factor expression, and edema in the uterus are mediated by the phosphatidylinositol 3-kinase/Akt pathway. Endocrinology 2007, 148:2363-2374.

23. Hua K, Din J, Cao Q, Feng W, Zhang Y, Yao L, Huang Y, Zhao Y, Feng Y: Estrogen and progestin regulate HIF-1alpha expression in ovarian cancer cell lines via the activation of Akt signaling transduction pathway. Oncol Rep 2009, 21:893-898.

24. Laughner E, Taghavi P, Chiles K, Mahon PC, Semenza GL: HER2 (neu) signaling increases the rate of hypoxia-inducible factor 1alpha (HIF-1alpha) synthesis: novel mechanism for HIF-1-mediated vascular endothelial growth factor expression. Mol Cell Biol 2001, 21:3995-4004.

25. Li YM, Zhou BP, Deng J, Pan Y, Hay N, Hung MC: A hypoxia-independent hypoxia-inducible factor- 1 activation pathway induced by phosphatidylinositol-3 kinase/Akt in HER2 overexpressing cells. Cancer Res 2005, 65:3257-3263.

26. Vaupel P, Mayer A, Hockel M: Tumor hypoxia and malignant progression. Methods Enzymol 2004, 381:335-354.

27. Semenza GL: Defining the role of hypoxia-inducible factor 1 in cancer biology and therapeutics. Oncogene 2010, 29:625-634.

28. Mendez O, Zavadil J, Esencay M, Lukyanov Y, Santovasi D, Wang SC, Newcomb EW, Zagzag D: Knock down of HIF-1alpha in glioma cells reduces migration in vitro and invasion in vivo and impairs their ability to form tumor spheres. Mol Cancer 2010, 9:133.

29. Lu X, Yan CH, Yuan M, Wei Y, Hu G, Kang Y: In vivo dynamics and distinct functions of hypoxia in primary tumor growth and organotropic metastasis of breast cancer. Cancer Res 2010, 70:3905-3914.

30. Mazumdar J, Dondeti V, Simon MC: Hypoxia-inducible factors in stem cells and cancer. J Cell Mol Med 2009, 13:4319-4328.

31. Krishnamurthy P, Ross DD, Nakanishi T, Bailey-Dell K, Zhou S, Mercer KE, Sarkadi B, Sorrentino BP, Schuetz JD: The stem cell marker Bcrp/ABCG2 enhances hypoxic cell survival through interactions with heme. J Biol Chem 2004, 279:24218-24225.

32. Zhou DJ, Pompon D, Chen SA: Stable expression of human aromatase complementary DNA in mammalian cells: a useful system for aromatase inhibitor screening. Cancer Res 1990, 50:6949-6954.

33. Yue W, Zhou D, Chen S, Brodie A: A new nude mouse model for postmenopausal breast cancer using MCF-7 cells transfected with the human aromatase gene. Cancer Res 1994, 54:5092-5095.

34. Jelovac D, Sabnis G, Long BJ, Macedo L, Goloubeva OG, Brodie AM: Activation of mitogen-activated protein kinase in xenografts and cells during prolonged treatment with aromatase inhibitor letrozole. Cancer Res 2005, 65:5380-5389.

35. Sabnis G, Goloubeva O, Gilani R, Macedo L, Brodie A: Sensitivity to the aromatase inhibitor letrozole is prolonged after a "break" in treatment. Mol Cancer Ther 2010, 9:46-56.

36. Burks SR, Macedo LF, Barth ED, Tkaczuk KH, Martin SS, Rosen GM, Halpern HJ, Brodie AM, Kao JP: Anti-HER2 immunoliposomes for selective delivery of electron paramagnetic resonance imaging probes to HER2-overexpressing breast tumor cells. Breast Cancer Res Treat 2010, 124:121-131.

37. Macedo LF, Guo Z, Tilghman SL, Sabnis GJ, Qiu Y, Brodie A: Role of androgens on MCF-7 breast cancer cell growth and on the inhibitory effect of letrozole. Cancer Res 2006, 66:7775-7782.

38. Schech AJ, Nemieboka BE, Brodie AH: Zoledronic acid inhibits aromatase activity and phosphorylation: potential mechanism for additive zoledronic acid and letrozole drug interaction. J Steroid Biochem Mol Biol 2012, 132:195-202

39. Stroka DM, Burkhardt T, Desbaillets I, Wenger RH, Neil DA, Bauer C, Gassmann M, Candinas D: HIF-1 is expressed in normoxic tissue and displays an organ-specific regulation under systemic hypoxia. FASEB J 2001, 15:2445-2453.

40. Jiang BH, Semenza GL, Bauer C, Marti HH: Hypoxia-inducible factor 1 levels vary exponentially over a physiologically relevant range of $\mathrm{O} 2$ tension. Am J Physiol 1996, 271:C1172-C1180.

41. Bergstraesser LM, Weitzman SA: Culture of normal and malignant primary human mammary epithelial cells in a physiological manner simulates in vivo growth patterns and allows discrimination of cell type. Cancer Res 1993, 53:2644-2654

42. Fang $Y$, Sullivan $\mathrm{R}$, Graham CH: Confluence-dependent resistance to doxorubicin in human MDA-MB-231 breast carcinoma cells requires hypoxia-inducible factor-1 activity. Exp Cell Res 2007, 313:867-877.

43. Paltoglou SM, Roberts BJ: Role of the von Hippel-Lindau tumour suppressor protein in the regulation of HIF-1alpha and its oxygen- 
regulated transactivation domains at high cell density. Oncogene 2005, 24:3830-3835.

44. Semenza G: Signal transduction to hypoxia-inducible factor 1. Biochem Pharmacol 2002, 64:993-998.

45. Yuan Y, Hilliard G, Ferguson T, Millhorn DE: Cobalt inhibits the interaction between hypoxia-inducible factor-alpha and von Hippel-Lindau protein by direct binding to hypoxia-inducible factor-alpha. J Biol Chem 2003, 278:15911-15916.

46. Wang GL, Semenza GL: General involvement of hypoxia-inducible factor 1 in transcriptional response to hypoxia. Proc Natl Acad Sci U S A 1993, 90:4304-4308

47. Sabnis $G$, Brodie A: Understanding resistance to endocrine agents: molecular mechanisms and potential for intervention. Clin Breast Cancer 2010, 10:E6-E15.

48. Pore N, Jiang Z, Shu HK, Bernhard E, Kao GD, Maity A: Akt1 activation can augment hypoxia-inducible factor-1alpha expression by increasing protein translation through a mammalian target of rapamycinindependent pathway. Mol Cancer Res 2006, 4:471-479.

49. Sudhagar S, Sathya S, Lakshmi BS: Rapid non-genomic signalling by 17beta-oestradiol through c-Src involves mTOR-dependent expression of HIF-1alpha in breast cancer cells. Br J Cancer 2011, 105:953-960.

50. Allen JD, Schinkel AH: Multidrug resistance and pharmacological protection mediated by the breast cancer resistance protein (BCRP/ ABCG2). Mol Cancer Ther 2002, 1:427-434.

51. Doyle LA, Ross DD: Multidrug resistance mediated by the breast cancer resistance protein BCRP (ABCG2). Oncogene 2003, 22:7340-7358.

52. Gilani RA, Kazi AA, Shah P, Schech AJ, Chumsri S, Sabnis G, Jaiswal AK, Brodie AH: The importance of HER2 signaling in the tumor-initiating cell population in aromatase inhibitor-resistant breast cancer. Breast Cancer Res Treat 2012, 135:681-692.

53. Li X, Pan YZ, Seigel GM, Hu ZH, Huang M, Yu AM: Breast cancer resistance protein $B C R P / A B C G 2$ regulatory microRNAs (hsa-miR-328, $-519 \mathrm{c}$ and $-520 \mathrm{~h}$ ) and their differential expression in stem-like ABCG2+ cancer cells. Biochem Pharmacol 2011, 81:783-792.

54. Yeo EJ, Chun YS, Park JW: New anticancer strategies targeting HIF-1. Biochem Pharmacol 2004, 68:1061-1069.

55. Feng $Y, Z$ Zhu H, Ling T, Hao B, Zhang G, Shi R: Effects of YC-1 targeting hypoxia-inducible factor 1 alpha in oesophageal squamous carcinoma cell line Eca109 cells. Cell Biol Int 2011, 35:491-497.

56. Generali D, Buffa FM, Berruti A, Brizzi MP, Campo L, Bonardi S, Bersiga A, Allevi G, Milani M, Aguggini S, Papotti M, Dogliotti L, Bottini A, Harris AL, Fox SB: Phosphorylated ERalpha, HIF-1alpha, and MAPK signaling as predictors of primary endocrine treatment response and resistance in patients with breast cancer. J Clin Oncol 2009, 27:227-234.

57. Rohwer N, Cramer T: Hypoxia-mediated drug resistance: novel insights on the functional interaction of HIFs and cell death pathways. Drug Resist Updat 2011, 14:191-201.

58. Flamant L, Notte A, Ninane N, Raes M, Michiels C: Anti-apoptotic role of HIF-1 and AP-1 in paclitaxel exposed breast cancer cells under hypoxia. Mol Cancer 2010, 9:191.

59. Mathieu J, Zhang Z, Zhou W, Wang AJ, Heddleston JM, Pinna CM, Hubaud A, Stadler B, Choi M, Bar M, Tewari M, Liu A, Vessella R, Rostomily R, Born D, Horwitz M, Ware C, Blau CA, Cleary MA, Rich JN, Ruohola-Baker H: HIF induces human embryonic stem cell markers in cancer cells. Cancer Res 2011, 71:4640-4652.

60. Oliveira-Costa JP, Zanetti JS, Silveira GG, Soave DF, Oliveira LR, Zorgetto VA, Soares FA, Zucoloto S, Ribeiro-Silva A: Differential expression of HIF-1alpha in CD44 + CD24-/low breast ductal carcinomas. Diagn Pathol 2011, 6:73.

61. Higashimura Y, Nakajima Y, Yamaji R, Harada N, Shibasaki F, Nakano Y, Inui $\mathrm{H}$ : Up-regulation of glyceraldehyde-3-phosphate dehydrogenase gene expression by HIF-1 activity depending on Sp1 in hypoxic breast cancer cells. Arch Biochem Biophys 2011, 509:1-8.

62. Wu KJ, Yang MH: Epithelial-mesenchymal transition and cancer stemness: the Twist1-Bmi1 connection. Biosci Rep, 31:449-455.

63. Fedele P, Calvani N, Marino A, Orlando L, Schiavone P, Quaranta A, Cinieri S: Targeted agents to reverse resistance to endocrine therapy in metastatic breast cancer: where are we now and where are we going? Crit Rev Oncol Hematol 2012, 84:243-251.

64. Berra E, Pages G, Pouyssegur J: MAP kinases and hypoxia in the control of VEGF expression. Cancer Metastasis Rev 2000, 19:139-145.
65. Minet E, Michel G, Mottet D, Raes M, Michiels C: Transduction pathways involved in Hypoxia-Inducible Factor-1 phosphorylation and activation. Free Radic Biol Med 2001, 31:847-855.

66. Zhao F, Mancuso A, Bui TV, Tong X, Gruber JJ, Swider CR, Sanchez PV, Lum JJ, Sayed N, Melo JV, Perl AE, Carroll M, Tuttle SW, Thompson CB: Imatinib resistance associated with $B C R-A B L$ upregulation is dependent on HIF-1alpha-induced metabolic reprograming. Oncogene 2010, 29:2962-2972

67. Liu L, Ning X, Sun L, Shi Y, Han S, Guo C, Chen Y, Sun S, Yin F, Wu K, Fan D: Involvement of MGr1-Ag/37LRP in the vincristine-induced HIF-1 expression in gastric cancer cells. Mol Cell Biochem 2007, 303:151-160.

68. Song X, Liu X, Chi W, Liu Y, Wei L, Wang X, Yu J: Hypoxia-induced resistance to cisplatin and doxorubicin in non-small cell lung cancer is inhibited by silencing of HIF-1alpha gene. Cancer Chemother Pharmacol 2006, 58:776-784.

69. Whipple RA, Matrone MA, Cho EH, Balzer EM, Vitolo MI, Yoon JR, loffe OB, Tuttle KC, Yang J, Martin SS: Epithelial-to-mesenchymal transition promotes tubulin detyrosination and microtentacles that enhance endothelial engagement. Cancer Res 2010, 70:8127-8137.

70. Zhang Y, Zhou G, Wang H, Zhang X, Wei F, Cai Y, Yin D: Transcriptional upregulation of breast cancer resistance protein by 17beta-estradiol in ERalpha-positive MCF-7 breast cancer cells. Oncology 2006, 71:446-455.

71. Majumder PK, Febbo PG, Bikoff R, Berger R, Xue Q, McMahon LM, Manola J, Brugarolas J, McDonnell TJ, Golub TR, Loda M, Lane HA, Sellers WR: mTOR inhibition reverses Akt-dependent prostate intraepithelial neoplasia through regulation of apoptotic and HIF-1-dependent pathways. Nat Med 2004, 10:594-601.

72. Faivre S, Kroemer G, Raymond E: Current development of mTOR inhibitors as anticancer agents. Nat Rev Drug Discov 2006, 5:671-688.

73. Thomas GV, Tran C, Mellinghoff IK, Welsbie DS, Chan E, Fueger B, Czernin J, Sawyers CL: Hypoxia-inducible factor determines sensitivity to inhibitors of mTOR in kidney cancer. Nat Med 2006, 12:122-127.

74. Greenberger LM, Horak ID, Filpula D, Sapra P, Westergaard M, Frydenlund HF, Albaek C, Schroder H, Orum H: A RNA antagonist of hypoxia-inducible factor-1alpha, EZN-2968, inhibits tumor cell growth. Mol Cancer Ther 2008, 7:3598-3608.

\section{doi:10.1186/bcr3609}

Cite this article as: Kazi et al: Nonhypoxic regulation and role of hypoxia-inducible factor 1 in aromatase inhibitor resistant breast cancer. Breast Cancer Research 2014 16:R15.

\section{Submit your next manuscript to BioMed Central and take full advantage of:}

- Convenient online submission

- Thorough peer review

- No space constraints or color figure charges

- Immediate publication on acceptance

- Inclusion in PubMed, CAS, Scopus and Google Scholar

- Research which is freely available for redistribution 